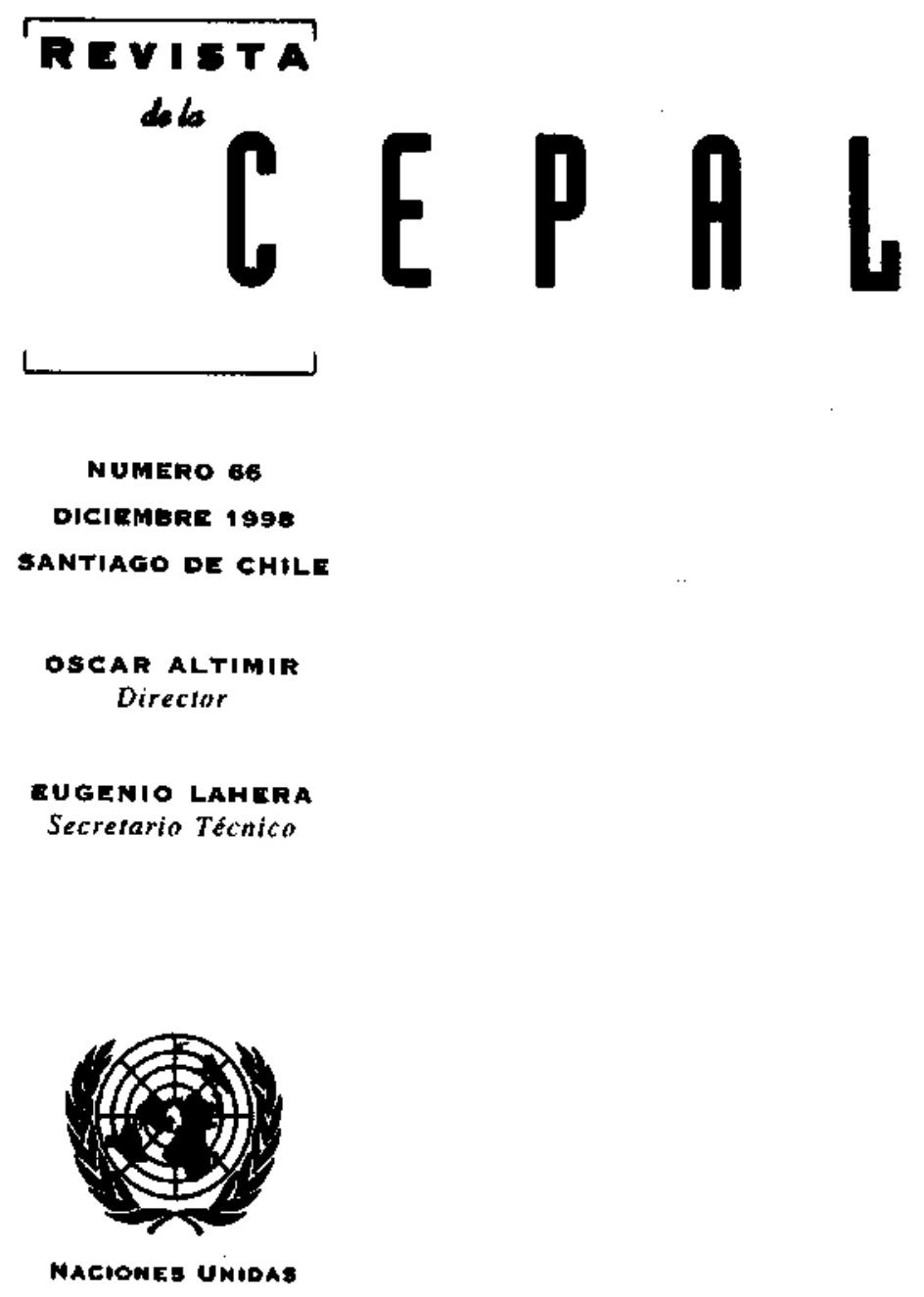


Más allá del Consenso de Washington: una vlsión desde la CEPAL

José Antonio Ocampo

La economía de Cuba

David barra y Jorge Máttar

La educación en América Latina: la demanda y la distribución importan

Nancy Birdsall, Juan Luis Londoño y Lesley' $O^{\prime}$ Connell

Determ/nantes de la desigualdad entre los hogares urbanos

Luis Felipe Jinénez L. y Nora Ruedi A.

Los compromisos de gestión en salud de Costa Rlca con una perspectlva comparativa

Ana Sojo

Una estrategia de desarrollo a partlr de complejos productivos

en torno a los recursos naturales

Joseph Ramos

Grandes empresas y grupos industriales latinoamerlcanos

Celso Garrido y Wilson Peres

Entre el control polftico y la eficiencia: evolución de los derechos de propiedad agraria en México

Gustavo Gordillo, Alain de Janvry y Elizabeth Sadoulet

Los aranceles y el Plan Real de Brasil

Renato Baumann, Josefina Rivero y Yohana Zavattiero

Publlcaciones recientes de la cepal 


\section{Más allá del Consenso de Washington: una visión desde la CEPAL}

\section{José Antonio Ocampo}

Secresario Ejecutivo de la cEPAL
Este artículo actualiza y complementa las ideas que ha planteado la CEPal a lo largo de la década de los noventa, a partir de la estrategia de transformación productiva con equidad y de los aportes de Fernando Fajnzylber. Tras unos párrafos introductorios (sección $I$ ), se examinan las características salientes de la situación actual de la región en el terreno macroeconómico, social y de la reestructuración productiva (sección II); se plantean orientaciones y políticas en cado uno de dichos frentes, con propuestas que destacan la necesidad común de avanzar en una segunda ola de reformas, que no se limiten a una mayor liberalización de los mercados, sino que busquen una interrelación pragmática entre Estado y mercado. En seguida se estudian los retos macroeconómicos, especialmente el manejo de la vulnerabilidad extema y el proceso de inversión, ahorro y financiamiento (sección III). Luego se analizan los espacios privilegiados de la mesoeconomía. en particular el desartollo tecnológico, las complementariedades estratégicas entre las decisiones de inversión, y la regulación de los servicios de infraestructura (sección IV). Por último, se examinan los temas de equidad y política social, especialmente los determinantes de la equidad, los espacios de la política social y las reformas de segunda generación en este frente (sección V). 


\section{Introducción}

A lo largo de los años noventa cl debate económico internacional y regional ha ido cambiando gradualmente de contenido. El énfasis inicial en los postulados del Consenso de Washington sobre ajuste macroeconómico y liberalización de los mercados ha ido dando paso a una visión más equilibrada, en la cual, como lo señalara recientemente el economista principal del Banco Mundial, se postulan más instrumentos y objetivos más amplios para el proceso de desarrollo (Stiglitz, 1998). Sin dejar de lado la estabilidad macroeconómica y las ventajas de contar con mercados más abiertos, el mejor funcionamiento de dichos mercados y de las estructuras públicas se visualiza cada vez más como un instrumento complementario para buscar objetivos que, más allá del crecimiento económico, incluyan también la equidad y la cohesión social, la sostenibilidad ambiental y el desarrollo democrático.

De acuerdo con este enfoque, se argumenta aquí que tras los avances logrados con las reformas estructurales en materia de estabilidad macroeconómica, apertura externa y racionalización del Estado, se requiere una segunda ola de reformas. Pero éstas no pueden limitarse a una mayor liberalización de los mercados, sino que deben buscar pragmáticamente una interrelación entre Estado y mercado que permita desarrollar tan extensa agenda. En algunos casos, puede ser además necesario reformar las reformas para res. ponder a los vacíos en la primera ola de reformas que se han hecho evidentes en los últimos años (FfrenchDavis, en prensa). El artículo actualiza y complementa las ideas que ha planteado la CEPAL a lo largo de los años noventa, a partir de la obra Transformación productiva con equidad (CEPAL, 1990) y de los aportes seminales de Fernando Fajnzylber que les sirvieron de sustento (véase, en especial, Fajnzylber, 1990).

El artículo hace un breve repaso inicial de las características de la situación actual en la región y luego aborda sucesivamente temas centrales del mancjo macroeconómico, del mesoeconómico y de la distribución de los frutos del desartollo. Desafortunadamente, las limitaciones de espacio impiden tratar aquí otros aspectos de igual trascendencia: los temas relativos a la sostenibilidad ambiental, al desarrollo democrático y a las estructuras gubernamentales. El carácter sucinto de nuestras consideraciones no hace suficiente justicia a cada uno de los temas tratados, pero sirve para delinear elementos fundamentales de la estrategia que viene proponiendo la CEPAL a los países de la región.

\section{II}

\section{Una visión panorámica de la región}

El hecho económico más destacado de los años noventa en América Latina y el Caribe es, sin duda, ta reanu-

\footnotetext{
口 Esta es una versión revisada de un documento preparado para el Seminario "Modelo y políticas de desartollo: Un tributo a Aníbal Pinto", organizado por el Banco Interamericano de Desarcollo y el Banco Nacional do Desenvolvimento Econônico (Rio de Janeiro, 22 y 23 de junio de 1998). El autor agradece los comentarios a una versión previa de este trabajo de Oscar Altinir, Osvaldo Rosales y Osvaldo Sunkel, así como la colaboración de diversas personas de la CEPML, en especial Ricardo Fifrench-Davis, Gunther Held y Stephany Griffith-Jones, quienes participaron en la elaboración de documentos anteriores, algunas de cuyas conclusiones se recogen en la parte II de este articulo. Conversaciones con Ostar Altimir y Samutel' Morley han sido muy útiles para aclarar algunas ideas de fa

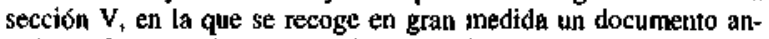
terior del autor (Ocampo, 1998a). Finalmente, el autor agradece también a Camilo Tovar por la elaboración de los cuadros y gráficos incluidos en este trabjjo.
}

dación del crecimiento. Este hecho ha sịdo mucho más evidente en América Latina, donde el ritmo medio de expansión del PIB entre 1990 y 1998 superó ampliamente el de la década anterior ( $3.5 \%$, contra $1.2 \%$ en los años ochenta) y se aceleró en todos los países, salvo en Paraguay. En el Caribe, por el contrario, el ritmo medio sigue siendo más bajo $(1.5 \%)$ y hay evidencia de desaceleración en varios países.

El crecimiento medio de la región sigue siendo inferior no sólo al que la cEPAL ha considerado deseable para cerrar las brechas que separan a la región de los países más desarrollados ( $6 \mathrm{a} 7 \%$ anual), sino a las tasas que exhibió la región entre los años cincuenta y setenta: $5.5 \%$ anual (gráfico 1). Esto refleja, además, la dificultad de recuperar los niveles de inversión ca- 
racterísticos de la fase de mayor dinamismo económico. El gráfico 2 muestra claramente este fenómeno: la tasa de inversión se ha recuperado, de un $20 \%$ del PIB a comienzos de la década a un $23024 \%$ cn promedio en los últimos años, aunque dista todavía de los niveles anteriores a la crisis de la deuda. Lo que es igualmente preocupante, el ahorro nacional se ha mantenjdo bajo, con lo cual el financiamiento de la inversión hoy depende en mayor proporción del ahorro externo (grafico 3).

El mayor crecimiento ha estado acompañado de más estabilidad macroeconómica. En realidad, la estabilidad alcanzada, inédita en varias décadas, y la prontitud con la cual las autoridades reaccionan con decisión frente a los desequilibrios financieros que se presentan constituyen señales claras de estabilidad y son, sin duda, fortalezas que le han dado una solidez relativa a la región en medio de las turbulencias generadas a partir de la crisis asiática (CEPAL, 1998c). La manifestación más clara de esta tendencia es la dismi-

GRAFCO

América Latina y el Caribe: Crecimiento del PIB

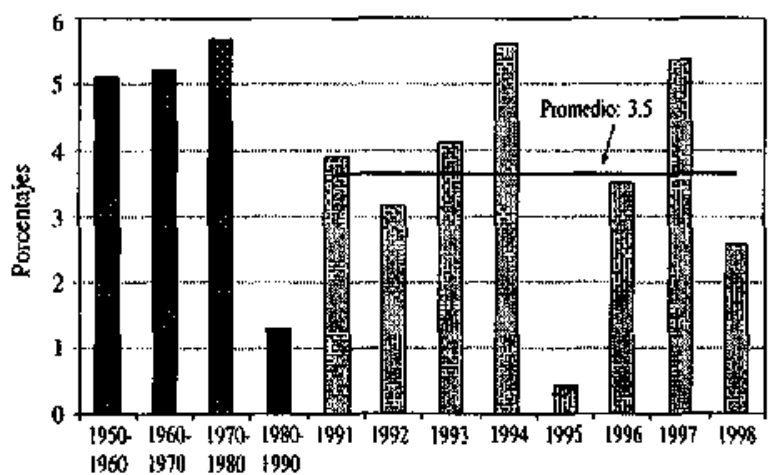

GRAFICO 2

América Latina y el Caribe: Formación bruta del capital fijo (\% del $P$ (B)

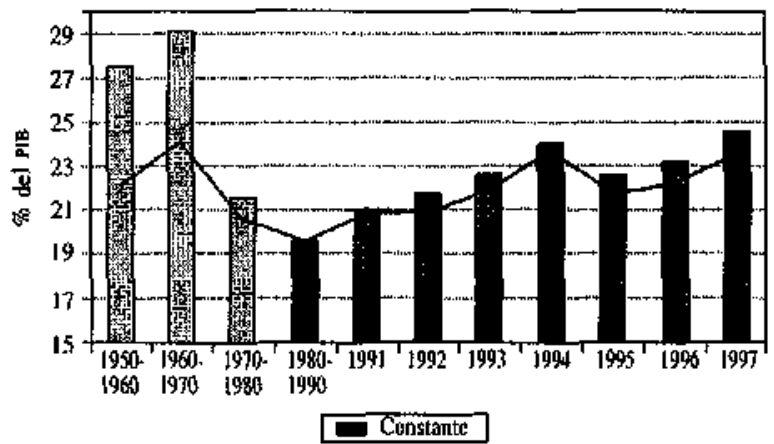

GRAFICO 3

América Latina y el Caribe: Ahorro nacional vs. formación bruta de capital

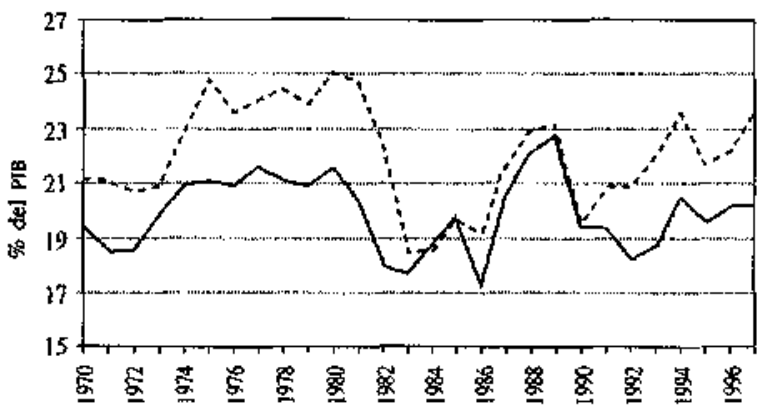

- Ahoro Nacional .... Forinación bruta de cápital

GRAFICO 4

Amérlca Latina y el Caribe: Crecimiento y flujos de capital

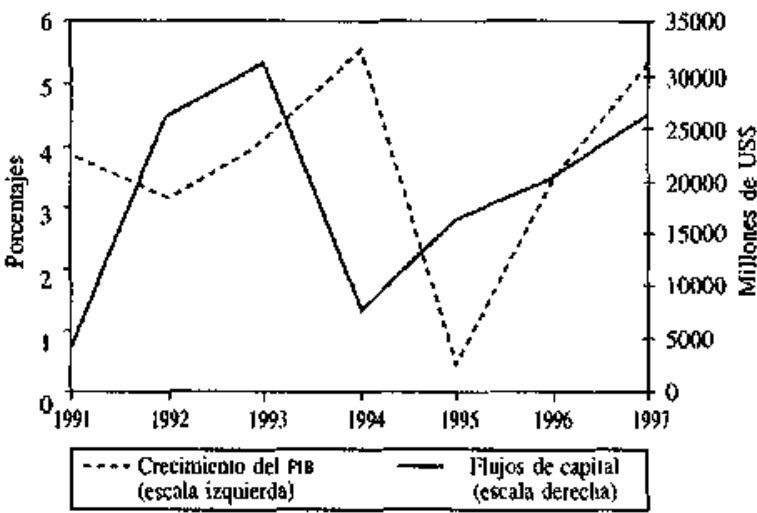

nución de la inflación. Aun después de controlar todos los procesos de hiperinflación, lo cual redujo la tasa de incremento de los precios de promedios de tres dígitos a comienzos de la década a $25.9 \%$ en 1995 , dicha tasa continuó reduciéndose al $10.5 \%$ en 1997. Por otra parte, aunque persisten problemas en varios países y hay fragilidades evidentes, la reducción de los déficit fiscales a niveles que han oscilado entre el 1 y el $2 \%$ del $\mathrm{ll} B$, en promedio, es otra señal de los avances en materia de estabilidad, como lo señalo el reciente informe de la CEPAL titulado El pacto fiscal (CEPAL, 1998b).

Hay también, sin embargo, elementos preocupantes en este frente. El primero es la gran sensibilidad del crecimiento económico a los ingresos de capital (gráfico 4), que tiene como uno de los elementos más preocupantes la tendencia a sustituir ahorro interno por ahorro externo (véase, al respecto, la sección III de este trabajo). El segundo es la gran sensibilidad de la ba- 
lanza comercial al crecimiento (gráfico 5), lo cual refleja, a su vez, la elevada elasticidad-ingreso de la demanda de importaciones que caracteriza hoy a las economias latinoamericanas. En este contexto, resulta paradójico el sesgo que exhiben los paquetes recientes de medidas de estabilización - enfasis en medidas fiscales y monetarias y, por el contrario, una gran renuencia a emplear los precios relativos (el tipo de cambio) como mecanismo de ajuste-, dado el generalizado proceso de revaluación real que ha experimentado la región en los años noventa. Esto puede redundar en menores tasas de inflación (por lo cual esta mezcla de política se justifica más en países con mayor tradición inflacionaria), pero puede conducir a una contracción mayor que la necesaria en la fase descendente del ciclo y, en general, a un comportamiento más inestable de la actividad económica.

En el frente exportador, el mayor dinamismo que han puesto en marcha los procesos de reforma es indiscutible. El volumen de las exportaciones ha venido creciendo a tasas de más de $10 \%$ anual a partir de 1993, muy superiores al $5 \%$ que caracterizó los años ochenta y el inicio de los noventa. El dinamismo del comercio intrarregional ha sido particularmente acentuado. El comercio recíproco del Mercosur y la Comunidad Andina creció $20 \%$ al af́o en el último lustro, lo que lo coloca entre los flujos de comercio más dinámicos del mundo. Este proceso ha coincidido con una importante diversificación exportadora, con la cual los productos primarios han perdido participación, al tiempo que ha aumentado la importancia relativa de las ventas externas de manufacturas. Este proceso ha sido particularmente notorio en México, pero es también válido para el conjunto de la región cuando se excluye dicho país (gráfico 6). En esta diversificación, el

QRAFICO 5

Amérlca Latina y el Carlbe: Creclmlento y balanza comercial

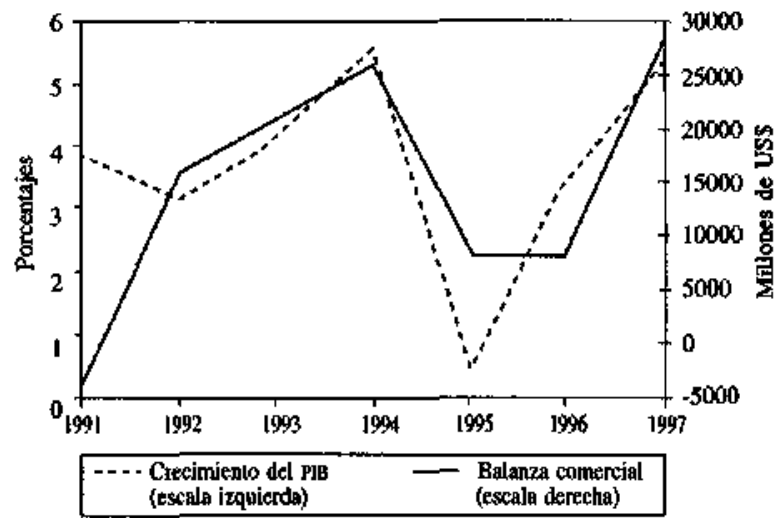

GRAFICO 6

\section{America Latina: Dlversiflicación} de exportaciones

\section{A. Total América Latina}

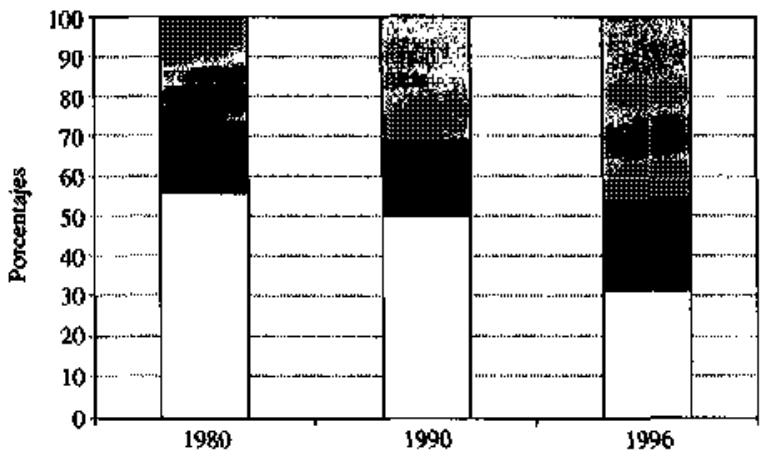

B. Amérlca Latina, excluido Míxico

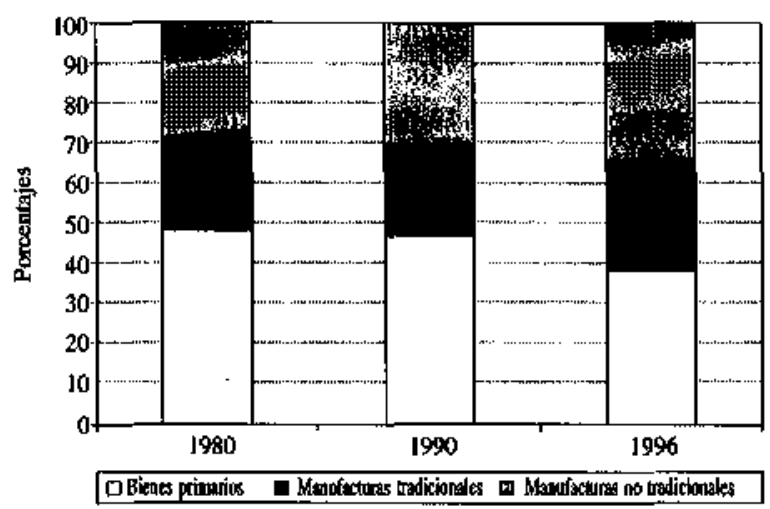

comercio intrarregional ha desempeñado un papel decisivo. El auge comercial se ha sustentado en una política de regionalismo abierto que ha roto tanto las prácticas regionales del pasado, incluida la tendencia a restringir los acuerdos de integración al comercio no competitivo, como las visiones más ortodoxas sobre integración económica (CEPAL, 1994).

El auge comercial ha coincidido, finalmente, con un crecimiento sin precedentes de la inversión extranjera directa: de poco más de 10000 millones de dólares a comienzos de la década a 55000 millones en 1997 (CEPAL, 1998e). Este crecimiento se ha sustentado fundamentalmente en tres procesos: la privatización de activos estatales en los sectores de servicios (telecomunicaciones, financieros, de energía y gas, etc.) y recursos naturales; la apertura o mejora de condiciones para la participación del capital privado en sectores de infraestructura y minería, y la reorganización de las empresas manufactureras multinacionales para mejorar su competitividad internacional en función de acuerdos regionales (incluido el Acuerdo de Libre 
Comercio de América del Norte y la Iniciativa de la Cuenca del Caribe ) o para defender su participación en mercados nacionales o subregionales. Por último, pero no menos importante, se ha producido un inédito auge de inversiones intrarregionales. El aumento de la inversion directa ha mejorado sensiblemente la estructura de las corrientes de capital recibidas por la región, lo cual, sin duda, explica en parte su solidez frente a las actuales turbulencias externas.

Aunque no existe todavía un balance completo de los procesos de reestructuración productiva a nivel sectorial y microeconómico, hay trabajos en curso que permiten avanzar algunas generalizaciones. Pese a grandes diferencias entre países y entre sectores, ha sido sorprendente la capacidad de adaptación de las empresas, tanto a las turbulencias de los años ochenta como a los cambios radicales del entorno macroeconómico y mesoeconómico en los noventa (por ejemplo, véase Peres, coord., 1997). Para ello han recurrido a diferentes estrategias, tanto defensivas como ofensivas (CEPAl, 1996; Benavente, Crespi, Katz y Stumpo, 1997; Katz, 1998). Las defensivas se centraron en: i) reestructuraciones organizacionales (reducción de niveles jerárquicos, concentración de las actividades en unidades o centros de negocios, profesionalización de la gestión); ii) reestructuraciones productivas con minima inversión (reducción de líneas de producción, mayor especialización y desverticalización, tanto importando insumos especializados como externalizando funciones productivas), y iii) nuevas estrategias de comercialización (importación de bienes, y su comercialización para completar la gama de productos, mejoras en las relaciones clientes-proveedores). Las estrategias ofensivas incluyeron las anteriores, pero agregaron importantes aumentos en nuevos equipos y tecnología, licencias internacionales y alianzas estratégicas con socios nacionales, regionales y transnacionales. La capacidad de respuesta demuestra, por lo demás, cierta solidez del aprendizaje adquirido en etapas anteriores del desarrollo. Los procesos de integración han desempeñado un papel muy ímportante en este proceso de adaptación, especíalmente en las ramas manufactureras con mayores contenjdos tecnológicos, permitiendo explotar economías de especialización y realizar alianzas estratégicas para servir a mercados que las empresas conocen mejor. La adaptación de las empresas más grandes ha resultado, en general, menos traumática que la de las PYME, pero incluso las primeras han perdido terreno frente a las transnacionales.

En general, sin embargo, sigue habiendo una importante brecha tecnologica entre la industria manu- facturera de la región y las mejores prácticas internacionales (cuadro 1). Aigunos países (en especial Argentina, Brasil, Colombia y México) están acortando esa distancia, proceso que se inició en casi todos ellos en los años ochenta y que en dos casos (Colombia y México) se interrumpió en la década actual. Un conjunto muy amplio de empresas han puesto en práctica estrategias defensivas de reorganización administrativa y de racionalización de sus procesos productivos, pero muchas menos han hecho el tránsito hacia estrategias ofensivas, invirtiendo fuertemente en equipos y tecnología y acercándose así a la frontera tecnológica internacional. En el caso de las ampliaciones, ha tendido a haber aumentos en el empleo, si bien con una relación capital-trabajo muy superior a la del pasado, y con tecnologías altamente informatizadas. En el caso de las empresas que han seguido exclusivamente estrategias defensivas, el incremento de la productividad ha contraído los niveles de empleo, con lo cual cl empleo industrial se ha reducido en forma marcada en casi todos los pafses de la región. El abaratamiento de los bienes de capital que ha acompañado la recuperación de los años noventa, a la cual aludimos anteriormente, ha contribuido también a este proceso.

Por otra parte, aunque en un grupo de países el sector agropecuario ha recuperado ritmos de crecimiento similares o superiores a los de los años setenta, esto no ha sucedido en el conjunto de la región. Además, en muchos países se observa un preocupante debilitamiento de las instituciones de desarrollo y transferencia de tecnología agropecuaria, en tanto que los productores más pequeños se han visto afectados por la desaparición o crisis de las entidades que les servían de apoyo, sin que hayan sido sustituidas por otros instru-

CUADRO 1

América Latina y el Caribe (algunos países): Brecha relativa de productividad con respecto a la industria estadounidense

\begin{tabular}{lcccc}
\hline & 1970 & 1980 & 1994 & 1997 \\
\hline Argentina & 0.42 & 0.41 & 0.55 & 0.67 \\
Brasil & 0.28 & 0.26 & 0.29 & 0.37 \\
Chile & 0.25 & 0.24 & 0.23 & $0.20^{\mathbf{h}}$ \\
Colombin & 0.29 & 0.25 & 0.37 & 0.34 \\
Costa Rica & & & 0.15 & $0.14^{\mathrm{h}}$ \\
Jamaica & 0.26 & 0.16 & 0.16 & $0.13^{\mathrm{b}}$ \\
México & 0.32 & 0.30 & 0.44 & $0.38^{\mathbf{b}}$ \\
Perú & 0.33 & 0.25 & 0.16 & 0.15 \\
Uruguay & 0.35 & 0.22 & 0.20 & $0.22^{\prime \prime}$ \\
\hline
\end{tabular}

Fuente: Katz (1998).

¿ 1995 .

b 1992 .

r 1994. 
mentos con igual o mayor efectividad (Ocampo, 1998b).

Los estudios existentes indican asimismo que la poblacion bajo los niveles de pobreza aumentó en forma marcada en los años ochenta. En los años noventa la situación ha mejorado en la mayoría de los países de la región, pero igualmente, con pocas excepciones, el porcentaje de hogares pobres es superior al de antes de la crisis de la deuda. Mientras en 1980 el 35\% de los hogares de América Latina se encontraba en situación de pobreza, y en 1990 dicha proporción se había elevado al 41\%, en 1994 se mantenía en el 39\% (desafortunadamente, no existen estimaciones similares para el Caribe ni cálculos globales más recientes para cl conjunto de América Latina). ${ }^{1}$ En términos de distribución del ingreso, la década de los ochenta fue también de deterioro. La expectativa de que la renovación del crecimiento económico revertiría dicha tendencia no se ha materializado $y$, por el contrario, ha habido deterioro en algunos países, de manera que los niveles de desigualdad se encuentran hoy por encima de los ya elevados que existían antes de la crisis de la deuda (CEPAL, 1997; B1D, 1997; Morley, 1995).

En los años noventa existen dos tendencias particularmente preocupantes en el mercado laboral, que generan presiones adicionales hacia la desigualdad. La primera es la disparidad creciente entre las remuneraciones de los trabajadores más calificados y las de aquellos que cuentan con menores niveles de calificación (CEPAL, 1997). Esta brecha aumentó en forma casi generalizada en los países de América Latina durante el primer lustro de los años noventa (grafico 7). La segunda es la escasa generación de empleo formal y el consecuente deterioro de la calidad de los empleos. $\mathrm{De}$ acuerdo con las estimaciones de la orr (1997), poco más de ocho de cada diez puestos de trabajo creados en los años noventa corresponden a ocupaciones de baja calidad en el sector informal. Aunque la informalidad sigue siendo la forma principal a través de la cual las economías latinoamericanas enfrentan la poca crea-

\footnotetext{
I Debido a la disminución de la pobreza en Brasil a ráz de la aplicación exitosa del Plan Real y del rejuste de los salarios mínimos que le sucedieron, el indicador global de la pobreza ha seguido disminuyendo cnsi seguramente en los últimos años. La reducción de la pobreza en un conjunto amplio de paises de la región en los antos noventa se destaca también en Morley (1997), con base en los resultados de un cstụdio comparativo promovido por el PNUD, el BaD y la CEPAL.
}

ción de puestos de trabajos, en el trienio 1995-1997 aumentó también la tasa de desempleo abierto en la mayoría de los países de la región (CEPAL, 1998d).

Por otra parte, en los años ochenta la crisis se reflejó en una disminución marcada del gasto público social por habitante y como proporción del PrB. En los noventa, se han recuperado en America Latina, aunque no en el Caribe, los niveles que se observaban antes de la crisis de la deuda. Esta recuperación, sin em. bargo, ha sido dispareja en los distintos países y se ha concentrado en los gastos que, según los estudios existentes, tienen la incidencia distributiva menos favorable (aquéllos en seguridad social). Por el contrario, los gastos en educación por habitante sólo regresaron a Inediados de los noventa a los niveles que eran característicos antes de la crisis (CEPAL, 1998b, cap.VI).

GRAFICO 7

América Latina: Brecha salarial

\section{A. Profesionales/traba|adores formales}

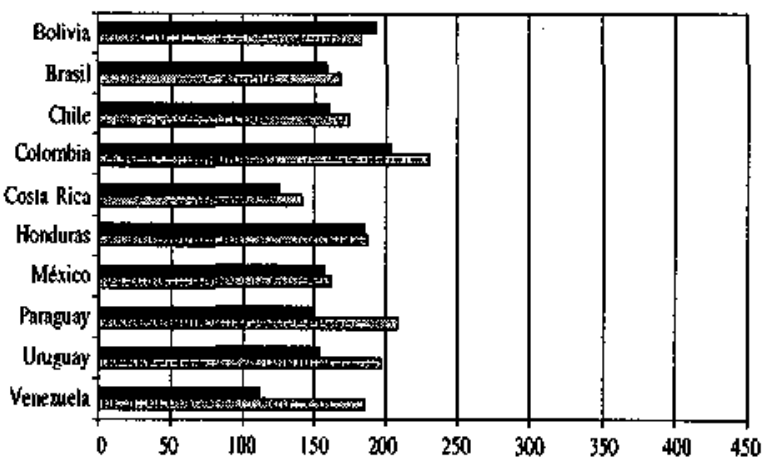

\section{B. Profesionalestraba|adores no formales}

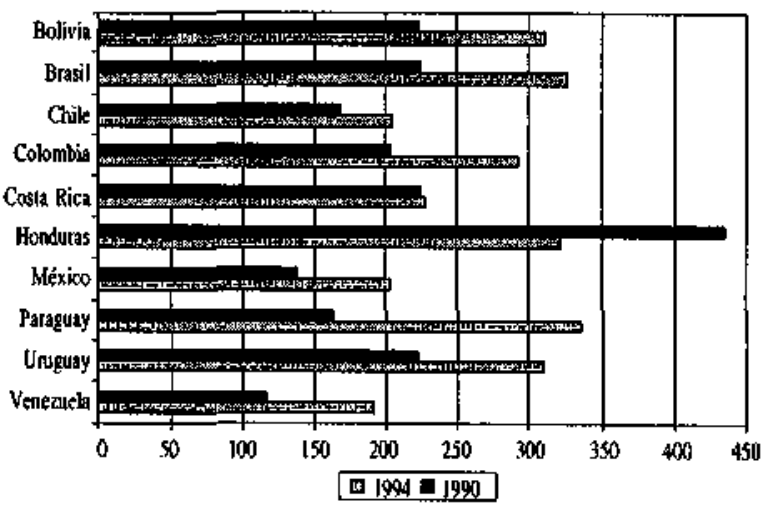




\section{III}

\section{Los retos macroeconómicos}

La recuperación de elevados grados de estabilidad macroeconómica, la valoración positiva de las oportunidades que ofrece el regionalismo abierto en el contexto actual de globalización y la búsqueda de estructuras estatales más eficaces y eficientes son logros destacados de la reestructuración económica que ha tenido lugar en América Latina y el Caribe en las últimas décadas. Sin embargo, según hemos visto, persisten dos elementos preocupantes en el frente macroeconómico: la elevada sensibilidad del crecimiento a los flujos externos de capital y la recuperación insuficiente de los niveles de inversión.

\section{El manejo de la vulnerabilidad externa}

La crisis asiática se ha sumado, en los años noventa, al efecto tequila de 1994-1995 y a la crisis del sistema monetario curopeo de 1992-1993 y, por supuesto, en la década anterior, a la crisis de la deuda latinoamericana. La inestabilidad que caracteriza las corrientes internacionales de capital y que se ha manifestado de esta manera en las últimas décadas es inherente a su funcionamiento, como lo atestigua la historia económica ${ }^{2}$ y la ya extensa literatura sobre fallas de mercado asociadas a problemas de informacion. Como resultado, el mercado ha experimentado una sucesión de oleadas de expansión excesiva y pánicos financieros, indicando que tiende a crecer, primero, y a contraerse, después, más de lo que recomiendan los factores fundamentales de las economías. En la coyuntura actual, se ha hecho notorio otro fenómeno: el de las insuficiencias en la coordinación macroeconómica entre las naciones más influyentes en los mercados y la ausencia de instituciones internacionales apropiadas para manejar un mercado financiero sofisticado pero inestable.

No existe, en efecto, ninguna institución internacional que contribuya a evitar que se desarrollen bonanzas financieras insostenibles, y el Fondo Monetario Internacional sólo tiene una capacidad limitada para manejar las crisis posteriores. El Banco de Pagos In-

2 Para una perspectiva latinonmericana véase el ya clásico ensayo de Bacha y Diaz-Alejandro (1982). ternacionales ha avanzado en la expedición de normas sobre regulación y supervisión bancaria, pero la instrumentación de ellas ha sido limitada. Por su parte, las agencias calificadoras de riesgo, que deberían desempeñar un papel en este frente, tienden a acentuar en ver de amortiguar tales tendencias, como lo demuestra un reciente estudio del Centro de Desarrollo de la oCDE (Larraín, Reisen y von Maltzan, 1997).

Esto indica que el momento actual es oportuno para repensar el ordenamiento financiero internacional $y$, por el contrario, poco oportuno para considerar una liberalización adicional de dicho mercado, tema que se encuentra en discusión en torno al cambio de los estatutos del FMI para otorgarle un mandato en materia de convertibilidad de la cuenta de capitales. En este campo, la experiencia reciente indica dos cosas. En primer término, que el centro de atención debe ser el manejo de las bonanzas y no de las crisis, ya que estas últimas son, en muchos sentidos, el resultado de bonanzas mal manejadas. Este es un punto de vista esencial, ya que de alguna manera las instituciones existentes. en especial el FMi, han sido diseñadas únicamente para manejar crisis y carecemos, por el contratio, de instrumentos apropiados para alertar sobre la gestación de bonanzas insostenibles y, mejor aún, prevenir a tiempo su desarrollo. En segundo térnino la ausencia de un marco regulatorio apropiado a nivel internacional justifica la adopción de medidas nacionales que estén orientadas precisamente a controlar las bonanzas que las autoridades consideren insostenibles, en especial los sistemas de encajes a pasivos externos que han venido utilizando con éxito Colombia y Chile. El diseño de mecanismos internos apropiados para manejar la volatilidad de los flujos financieros externos ha sido, de hecho, uno de los temas centrales de reflexión de la CEPAL en los últimos años (véanse, por ejemplo, CEPAL, 1998a, parte tercera, y Ffrench-Davis y Reisen, comps., 1997).

Este diseño debe estar cimentado en el desarrollo de instrumentos de política $\mathrm{c}$ instituciones apropiadas para el manejo de las bonanzas o, lo que es equivalente, para la prevención de las crisis. El exceso de atencion al manejo de las crisis ignora, en realidad, un hecho que debería ser evidente: que el margen de ma- 
niobra con que cuentan las autoridades es mayor en las bonanzas que en las crisis. Una vez que se desencadena esta última, las autoridades no tienen más alternati. va que adoptar las medidas apropiadas para restablecer la confianza, lo cual significa en la práctica adoptar medidas procíclicas. En efecto, una bonanza caracterizada por la expansión excesiva del gasto público y privado genera inevitablemente un ajuste, cuya severidad es función del exceso de gasto precedente. Así, un aumento insostenible del gasto público, basado en ingresos tributarios transitorios y el acceso extraordinario al crédito externo, da lugar a un severo ajuste posterior. Un endeudamiento excesivo del sector privado, basado en una subestimación de los riesgos de dicho endeudamiento, da lugar a una severa contracción crediticia posterior que, en el contexto de los menores ritmos de crecimiento y las elevadas tasas de interés reales que caracterizan las fases de ajuste, puede llevar a pérdidas de cartera equivalentes a elevadas proporciones del PIB, como lo atestigua un conjunto amplio de crisis bancarias regionales y extrarregionales. Una sobrevaluación de la moneda basada en ingresos de capital transitorios o unos precios extraordinarios de productos de exportación, dan lugar a una fuerte presión sobre la tasa de cambio o las tasas de interés, una vez que dichos fenómenos transitorios desaparecen.

Aś las cosas, el reto fundamental para el manejo de la vulnerabilidad externa de las economías de la region es diseñar instrumentos apropiados para administrar las bonanzas, es decir, para prevenir las crisis. Algunos han sido ampliamente destacados, en especial aquellos relacionados con el establecimiento de regulaciones prudenciales fuertes de los sistemas financieros internos, que incluyan tanto la capitalización adecuada de las instituciones como esquemas de supervisión orientados a evitar que los intermediarios asuman riesgos inmanejables durante los períodos de bonanza. Uno de los corolarios de lo anterior es que, en presencia de una vulnerabilidad mayor que aquella que caracteriza a las naciones más industrializadas, los requisitos de capital de los intermediarios financieros deben ser más severos que los que ha propuesto el Comitê de Basilea del Banco de Pagos Internacionales. La supervisión prudencial de los créditos externos de corto plazo, particularmente aquellos intermediados a través del sistema financiero interno, debe ser también severa. Cautela especial debe adoptarse además en torno al uso, como garantía de los créditos, de activos cuyos precios son excesivamente cíclicos. Por este motivo, es adecuado en los períodos de inflación de activos hacer más severos los requisitos que deben llenar dichas garantías. Por supuesto, como to indican también las controversias recientes sobre la crisis asiática, las autoridades deben dar señales claras de que no saldrán en ningún caso a salvar el patrimonio de los dueños de las entidades financieras ( $y$ actuar en consecuencia si se desencadena una crisis), evitando generar problemas de "riesgo moral" y exigiendo transparencia en las finanzas corporativas, para prevenir riesgos adiciona* les de las carteras bancarias.

En el frente cambiario, el mercado ha premiado una y otra vez una buena estructura del endeudamiento externo; por este motivo, los esfuerzos orientados a mejorar el perfil temporal de los pasivos externos públicos y privados desempeñan un papel esencial. En el primer caso, debe ejercerse de preferencia un control directo sobre los pasivos de todas las entidades públicas, aun las autónomas y descentralizadas. En el segundo, como ya se señaló, es conveniente un sistema de encajes (o impuestos) a pasivos en moneda extranjera. Este esquema ayuda a mejorar dicha estructura $y$, al menos según algunos estudios, tiende también a reducir (por lo menos temporalmente) la magnitud de los flujos durante las bonanzas, con lo cual cumple el papel adicional de moderar las presiones cambiarias y monetarias que se generan durante estos períodos. El sistema diseñado por Argentina, de establecer elevados requisitos de liquidez a las entidades financieras como contrapartida de sus pasivos de corto plazo, puede cumplir un papel muy similar. Dentro de ciertos márgenes, la esterilización de los efectos monetarios de los aumentos de reservas que generan los mayores flujos ha probado también su utilidad para evitar que éstos se traduzcan en una ampliación excesiva del crédito interno. Por último, una flexibilidad administrada del tipo de cambio puede ser también útil. Para ello es necesario, sin embargo, que se permita que dicha flexibilidad opere en ambos sentidos, evitando el sesgo revaluacionista que se ha hecho evidente en muchos países de la región durante los años noventa.

El manejo de la vulnerabilidad externa exige también diseñar instrumentos fiscales apropiados para tal fin. Ellos deben incluir, en primer término, mecanismos institucionales que obliguen a esterilizar ingresos fiscales transitorios. Las experiencias parciales que se han venido acumulando con fondos de estabilización de ingresos fiscales provenientes del manejo de productos básicos deben extenderse al manejo de ingresos tributarios transitorios. Esto indica, por lo demás, 
que los objetivos fiscales deben fijarse, no en función del deficit fiscal corriente, sino de alguna medida del déficit estructural, como acontece en los países de la Organización de Cooperación y Desarrollo Económi$\cos$ (OCDE). Más aún, muchos países pueden inclinarse por compensar total o parcialmente las tendencias de corto plazo del gasto privado con movimientos en sentido contrario de los gastos o los ingresos públicos, permitiendo de paso que el endeudamiento público compense las tendencias del endeudamiento privado. La solidez de la situación fiscal, mirada tanto en términos de flujos (superávit o déficit) como de saldos (deuda) es, conjuntamente con la de los sistemas financieros internos, esencial para contar con la libertad necesaria para manejar perturbaciones externas desfavorables.

\section{Inverslón, ahorro y financlamiento}

Las relaciones causales entre ahorro, inversión y crecimiento $0^{3}$ operan en múltiples direcciones, generando círculos virtuosos (o viciosos): un mayor nivel de inversión genera más crecimiento, que a su vez eleva el ahorro y facilita el financiamiento de mayores niveles de inversión. Sin embargo, la evidencia empírica tien. de a respaldar las líneas causales keynesianas, al establecer que Ios mayores niveles de ahorro son un efecto más que una causa del mayor crecimiento económico, y que este último induce, a través de efectos aceleradores, mayores niveles de inversión. Esto indica que las mejorías (o deterioros) "autónomos" de la tasa de crecimiento tienden a reproducirse, a través de sus efectos positivos en los flujos de ahorro e inversión.

Por otra parte, las altas tasas de inversión están invariablemente relacionadas con elevados niveles de ahorro interno. Esta asociación deriva fundamentalmente de los límites que existen para mantener déficit en cuenta corriente (ahorro externo) elevados. Existe además, amplia evidencia de una fuerte sustitución entre ahorro interno y externo (gráfico 8), que refuerza el vínculo precedente $e$ indica que una parte importante de las variaciones en este úllimo se reflejan en mayor o menor consumo público o privado. ${ }^{4}$ Un mayor ahorro interno es, además, esencial para enfrentar episo-

3 Entre muchas contribuciones recientes al debate sobre la interrelación de estas variables, véanse Held y Uthoff (1995), CEPAL (1996), Schmidt-Hebbel, Servén y Solimano (1996), Uthoff y Titelman (1997) y Gavin, Hausinann y Talvi (1997).

${ }^{4}$ La mitad, de acuerdo con estimaciones de CLPAL (1996) y Uthoff y Titelman (1997).
GRAFICO 8

América Latina: Ahorro interno y ahorro externo

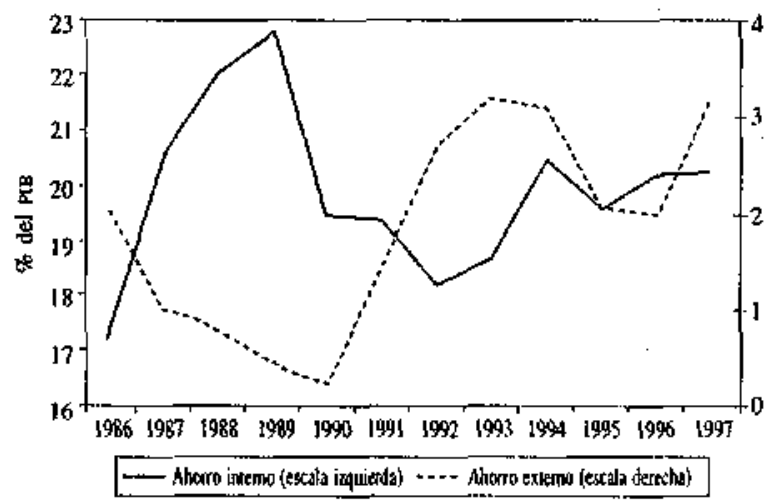

dios de altas entradas de capital, acumulando reservas internacionales para esterilizar el efecto expansivo de dichos capitales y preservar un entorno económico estable.

Los altos niveles de ahorro interno están correlacionados, a su vez, con altas tasas de ahorro público y empresarial. La importancia de este último, en la forma de utilidades no distribuidas y reservas de depreciación, fue una característica notoria de los países asiáticos durante su fase de rápido crecimiento, y lo ha sido igualmente de la experiencia reciente de Chile. Esto indica que la clave de un crecimiento acelerado es un nexo fuerte entre inversion y utilidades de las empresas, como lo señalan algunos trabajos recientes (por ejemplo, Akyïz y Gore, 1994). El incentivo a la retención de utilidades implícito en el sistema tributario parece haber sido uno de los elementos importantes del elevado ahorro empresarial de Chile. ${ }^{5}$ Por el contrario, no existe evidencia sólida en América Latina (e incluso en general) que avale los efectos positivos de altas tasas de interés sobre el ahorro. Esto indica esencialmente que los efectos de sustitución en los cuales se sustenta la relación positiva entre estas dos variables se ven contrarrestados por los efectos -ingreso de las mayores tasas de interés, que tienden a aumentar el consumo. Las tasas de interés tienen, en cualquier caso, un papel importante en la intermediación financiera, en

\footnotetext{
5 Sin embargo, incentiyos elcvados de este tipo también generan efectos desfavorables, que no han estado ausentes en el caso chileno. En particular, facilitan la concentración de la propiedad. Ademís, generan un incentivo adicional a prácticas de evasión tributaria que son connaturales a cualquier sistema de impuestos a las rentas de capital, corno las de presentar los gastos de consumo de los duchios de las empresas como gastos intermedios de estas últimas.
} 
la asignación de recursos que se genera a través de ella y en la regulación de los flujos de capital. El ahorro de los hogares es mucho más sensible a mecanismos de ahorro forzoso, especialmente previsional pero también de otro típo (por ejemplo, requisitos de ahorro previo asociados a la obtención de créditos de vivienda, obligación de mantener una parte de la remuneración salarial en fondos de cesantía, etc.). Vale la pena resaltar que la importancia del ahorro público señalada al comienzo de este párrafo establece también una conexión importante entre ahorro y tributación. Aunque una reducción de la tributación puede inducir mayor ahorro privado (y existe así por esta vía una sustitución entre ahorro público y privado), tenderá a traducirse generalmente, a través de sus efectos sobre la cuentas públicas, en menores niveles de ahorro nacional. En otras palabras, la tributación tiene efectos similares a los mecarismos de ahorro forzoso. ${ }^{6}$

En este contexto, las amplias expectativas que ha despertado la reforma de los sistemas previsionales, que los transforma de esquemas de reparto en sistemas de capitalización, sólo están parcialmente fundadas. El efecto más importante de estas reformas es el que tienen sobre los déficit públicos, pues permiten disminuir o eliminar los desahorros que han tendido a generarse con los sistemas de reparto. Los nuevos sistemas pue. den también hacer una contribución importante a la oferta de recursos financieros de largo plazo, aunque la canalización productiva de éstos depende de que se desarrollen mecanismos institucionales apropiados. Sin embargo, la contribución bruta al ahorro que hacen estos sistemas tiende a ser pequeî́a (poco más del $3 \%$ del PIB durante los años noventa en el caso chileno) y sus efectos netos dependen de que los ahorros forzosos que genere el sistema previsional no estén contrarestados con menores ahorros voluntarios. En el caso chileno, este último requisito no se ha cumplido, ya que el mayor ahorro previsional parece haber sido sustituido por desahorro personal voluntario, facilitado por una amplia disponibilidad de bienes y de crédito de consumo, producto de la liberalización comercial y financiera. Por otro lado, el costo fiscal de estos procesos de reforma es elevado y debe valorarse adecuadamente antes de ponerlos en marcha (CEPAL, 1998b, cap.VII).

El carácter irreversible de las decisiones de inversión indica, por su parte, que esta variable es sensible a reglas de juego y entornos macroeconómicos estables. Las medidas destinadas a reducir la volatilidad macroeconómica tienen, por lo tanto, efectos positivos

6 Esto supone, por supuesto, que la mayor tributación no se refleja en gastos excesivos de consutno público. sobre ella. También los tienen las inversiones públicas complementarias, especialmente en infraestructura y la disponibilidad de crédito externo o interno de largo plazo. También son gravitantes los precios relativos de los bienes de capital (que en muchos países están fuertemente asociados a la tasa de cambio real) $y$, en países con mercados accionarios más desarrollados, los precios de las acciones. Los incentivos fiscales específicos, como los que buscan fomentar inversiones en actividades con alto contenido tecnológico, pueden tener efectos favorables, pero aquellos que incentivan la inversión en términos más generales pueden ser costosos en relación con sus posibles beneficios.

La eficiencia con la cual el mercado fínancicro canaliza recursos de ahorro hacia la inversión es también esencial en el proceso de desarrollo. Para ello es importante la creación de instituciones e instrumentos apropiados, con distintos perfiles de rentabilidad, riesgo y liquidez, la provision de servicios con bajos costos de intermediación, y la regulación y supervisión prudencial. El sector público desempeña un papel fundamental en garantizar todos estas condiciones. Ya nos hemos referido a la regulación prudencial, materia sobre la cual ha habido avances importantes en muchos países latinoamericanos. Los elevados costos de los servicios financieros en casi toda la región indican que existe un campo propicio para fomentar prácticas competitivas, asf como para reducir incertidumbres macroeconómicas que se reflejan en elevados márgenes de intermediación.

Concentremos, sin embargo, la atención sobre el primero de los instrumentos mencionados. Las dos tareas fundamentales que debe enfrentar la acción pública en este ámbito son la de garantizar que las empresas pequeñas y las familias pobres tengan acceso al crédito, y la de fomentar la disponibilidad de fondos de largo plazo para el financiamiento de la inversión. Las líneas de crédito a través de bancos de "segundo piso", los subsidios a la demanda y/o a los costos de transacción, y el diseño de fondos de garantías o mecanismos de aseguramiento, son los instrumentos básicos para asegurar una adecuada cobertura de servicios financieros a las pequeñas empresas y a los hogares pobres, urbanos y rurales. Pese al avance logrado en algunos países, dicha cobertura es aún muy precaria.

La tendencia de ahorradores y acreedores a reducir el riesgo, concentrando sus operaciones en transacciones de corto plazo y renta fija, exige también en este campo un papel activo del sector público. Los mecanismos más importantes son la creación de nuevas 
instituciones o instrumentos (fondos de pensiones; otros inversionistas institucionales que incluyen fondos extranjeros; nuevos instrumentos para facilitar el financiamiento de la vivienda y la infraestructura privada; fondos o seguros de garantía, etc.); el diseño de marcos regulatorios y sistemas de incentivos apropiados, y la oferta de servicios financieros por bancos de desarrollo o fondos de capital de riesgo, públicos 0 mixtos. ${ }^{7}$ En este caso, al igual que en la provisión de servicios a pequeños agentes, casi todos los países han seguido contando en gran medida con instituciones públicas. De hecho, esta puede ser la solución apropiada, siempre que se establezcan reglas que garanticen el profesionalismo de sus actividades y se evite la interferencia política y sobre todo la tentación de convertir tales instituciones en mecanismos de canalización de subsidios, que condujo a su crisis en el pasado. Por otra parte, los avances en este frente, particularmente del mercado de capitales, están limitados por una característica estructural: el predominio de sociedades esencialmente familiares, que por supuesto es mayor en las economías más pequefias. Este es un factor central para el diseño de las normas regulatorias y de promoción del mercado (por ejemplo, aquellas que afectan el destino de los recursos de los fondos de pensiones). A falta de una oferta de acciones amplia, los bancos de desarrollo pueden contribuir mucho a canalizar los recursos hacia la inversión. Por último, aunque las empresas latinoamericanas hacen uso cada vez mayor del mercado internacional (emisiones en la bolsa de Nueva York, en particular), no se aprecia el surgimiento de mercados regionales de valores. Esta puede ser una de las áreas que la acción pública podría privilegiar en el futuro.

Estas consideraciones plantean tanto una amplia gama de acciones para mejorar los niveles de ahorro e inversión y los canales de transmisión entre ambos, como algunas recomendaciones de cautela en varias áreas (los efectos previsibles de las reformas previsio. nales, el impacto de reducciones en las tasas de tributación o aumentos de las tasas de interés sobre el ahorro). Una de las conclusiones más sugestivas es la de que los desplazamientos "autónomos" del crecimiento económico —es decir, independientes de los factores que determinan el proceso de ahorro e inversiónpueden generar cítculos virtuosos (o viciosos) que se reproducen a través de sus efectos sobre el ahorro y la inversión. En sus distintas variantes, la literatura sobre crecimiento económico identifica tres canales fundamentales. ${ }^{8} \mathrm{El}$ primero es aumentar el capital huma. no: sus efectos son de lenta gestación y su gran virtud es la complementariedad que establece entre crecimiento y equidad. El segundo es aceletar el cambio tecnologico. El tercero es explotar las complementariedades estratégicas de las decisjones de inversión. Los dos últimos también pueden influir positivamente sobre el crecimiento y la equidad. El aumento del capital humano se examinará en la sección $\mathrm{V}$ de este artículo. Las otras dos acciones pertenecen al ámbito de la mesoeconomía. A ella atenderemos a continuación.

\section{IV}

\section{Los espacios privilegiados de la mesoeconomía}

El funcionamiento de los mercados, su relación con el desarrollo institucional y la manera como uno y otro afectan el comportamiento microeconómico, han sido algunos de los temas centrales de las propuestas de la CEPAl en los últimos años. Así como una buena macroeconomía es necesaria para reducir o eliminar incerti-

\footnotetext{
7 La canalización de parte o la totalidad de las acciones de empresas privatizadas a través de las bolsas de valores y el liderazgo del gobiemo en la emisión de bonos de mayor plazo son también elementos importantes, como lo refleja la experiencia de varios países de la región. También es importante facilitar la emisión de bonos o acciones en el exterior, aunque en este caso no hay acciones directas de formento a la intermediación interna.
}

dumbres básicas que afectan el funcionamiento de los mercados, la manera como éstos operan afecta a su vez el comportamiento macroeconomico. En la propuesta de la CEPAL, por lo tanto, una buena macroeconomía depende de una buena mesoeconomía. La importancia que hemos otorgado al funcionamiento y regulación de los mercados financiero y cambiario en las secciones anteriores sirve como una primera comprobación de este aserto. El papel fundamental que desempeñan los

\footnotetext{
* Hay, por supuesto, otros que se relacionan con el contexto legal y sociopolítico. Véanse por ejemplo Barro y Sala-i-Martin (1995) y Barro (1997).
} 
factores señalados al final de la sección anterior sobre el crecimiento económico es otra comprobación.

Los temas esenciales de la mesoeconomía son los mercados inexistentes e incompletos y las imperfecciones de los mercados establecidos, así como la estrecha relación entre el funcionamiento de los mercados $y$ las instituciones formales e informales en las cuales se enmarcan (entidades las primeras como las organizaciones formales de regulación pública y las segundas como las costumbres, normas o patrones de comportamiento de los agentes). Los temas centrales están invariablemente asociados a fallas de mercado, tanto aquéllas resaltadas en la vieja literatura sobre competencia imperfecta -economías de escala, externalidades $\mathrm{y}$ bienes públicos-como problemas de información en los cuales ha hecho hincapié la literatura económica en las ultimas décadas. Obviamente, la posibilidad de corregir tales fallas con acciones públicas depende también de que se corrijan las no menos importantes fallas del gobierno, que incluyen la introducción de racionalidades no económicas ni sociales (burocráticas o clientelísticas) en el funcionamiento de las instituciones, los problemas de representación (principal-agente), el reflejo en su operación de los intereses económicos dominantes (es decir, los problemas de economía política), las oportunidades que genera la intervención del Estado para la captación de rentas y los problemas de información que afectan igualmente a las acciones gubernamentales.

La búsqueda de un equilibrio apropiado entre mercado y Estado es, por lo tanto, inherente a una buena mesoeconomía. Como es obvio, dicho equilibrio está necesariamente mediatizado por decisiones políticas fundamentales de cada sociedad. En la actual etapa del desarrollo de los países de la región, esto impone, en cualquier caso, la tarea activa de crear y reinventar instituciones, ya que muchas de las existentes están profundamente afectadas por patrones de comportamiento heredados del pasado o cargan el deterioro acumulado en un largo período de ajuste cconómico. Esto es cierto de instituciones públicas afectadas por proceso de burocratización o racionalidades corporativas y clientelísticas, como también de instituciones privadas, tales como gremios o asociaciones de produccion y sindicatos, que no han logrado adaptarse plenamente a los cambios en su entorno. El problema no se resuelve con la mera eliminación de instituciones inoperantes, como está implícito en muchas propuestas de política. De hecho, la práctica ha demostrado que la peor de todas las "instituciones" es la ausencia de instituciones apropiadas para manejar los problcmas que analizaremos en esta sección. Por ejem- plo, una de las lecciones penosamente aprendidas en muchos países de la región ( $y$, peor aún, en algunas de las econonías en transición) es que la ausencia de regulaciones estatales apropiadas puede convertir las privatizaciones en masivas transferencias de riqueza e ingreso, sin que se logren los objetivos de eficiencia que se persiguen con ellas.

Aunque las esferas de acción en la mesoeconomía son amplias, concentraremos la atención en tres de ellas: el desarrollo tecnológico, las complementariedades cstratégicas de las decisiones de inversión y la regulación de los servicios de infraestructura. Estos temas, junto al funcionamiento de los mercados financieros, a los cuales hicimos alusión en la sección III, y aquellos relativos a regulaciones ambientales (que por limitaciones de espacio no se abordan en este ensayo) constituyen los espacios privilegiados de la mesoeconomía.

\section{Desarrollo tecnológico}

Los problemas que plantea el desarrollo tecnológico están íntimamente relacionados con el carácter "tácjto", no enteramentc formalizado, del conocimiento técnico (Katz, 1984; Katz y Kozakoff, 1998). Esto sig. nifica que no existe un manual perfectamente codificado (un blueprint) que pueda comprarse en el mercado $y$, por lo tanto, que la adquisición de este conocimiento está asociada a un proceso de aprendizaje. Este aprendizaje está, ademas, íntimamente ligado a la experiencia en la actividad productiva, es decir, involucra necesariamente un aprendizaje por la práctica. En efecto, la maestría en el manejo de una tecnología depen de de la experiencia en su uso, pero además la experiencia permite aprender con mayor facilidad nuevas tecnologías e innovar sobre las existentes. Más aún, las tecnologias generalmente requicren adaptación para poderlas aplicar en nuevos contextos productivos. Esto es notoriamente cierto en el caso de tecnologías no incorporadas (incluidas las técnicas de administración o de comercialización), pero lo es también para las incorporadas en equipos o en insumos especiales (una nueva variedad vegetal, por ejemplo).

Por cllo, el conocimiento técnico es tanto un requisito previo como un resultado del proceso productivo. A nivel individual y organizacional, da lugar a un proceso de maduración, a medida que se acumulan experiencias, se expanden las actividades actuales y se emprenden otras nuevas. Este proceso de maduración genera, por lo tanto, formas de capital humano individual y organizacional. En uno y otro caso, la capacidad de aprendizaje está ligada con la educación de las 
personas involucradas, de modo que se genera una complementariedad entre el capital humano tecnologico y el educativo. Este capital, por lo demás, no es plenamente apropiable: los conocimientos se pueden enseñar o transmitir, las personas que los han aprehendido se pueden mover entre organizaciones y, obviamente, cuando están incorporados en equipos o insumos, se pueden adquirir. Esto origina externalidades de diferente tipo que transforman tanto el capital tecnológico como el educativo, en una forma de capital social que podemos denominar "capital conocimiento". La acumulación de cste capital se facilita enormemente cuando existen instituciones apropiadas, "sistemas de innovación" que apoyen su desarrollo, que generen interacciones dinámicas entre el sistema educativo, los centros de investigación tecnológica y las propias empresas, y que permitan explotar plenamente las economías de escala de la investigación y las externalidades que caracterizan el conocimiento tecnologico (CEPAL, 1990 y 1996). Estas instituciones son, por lo tanto, elemento esencial del "capital conocimiento".

Debido a la íntima relación entre conocimiento técnico y experiencia productiva, existe una fuerte interdependencia entre usar tecnología y generarla. De hecho, la propia adaptación de tecnología puede dar lugar a innovaciones localizadas y la experiencia productiva acumulada a innovaciones de mayor alcance. Sin embargo, los avances innovativos están ligados a esfuerzos deliberados por generar nuevos procesos o nuevos productos o a la utilización de nuevos insumos, es decir, a esfuerzos explícitos de inversión. Las rentas específicas que obtiene la empresa innovadora tienen el carácter de rentas monopólicas, y constituyen el gran incentivo a dicha inversión, que se acrecienta con su protección legal. En contextos competitivos de dinamismo tecnológico, sin embargo, la inversión en tecnología se convierte en un requisito para la sobrevivencia misma de las empresas que operan en el mercado.

Las inversiones en este terreno involucran costos fijos, asociados a indivisibilidades de diferente tipo, y su rentabilidad esperada es incierta. Aún la imitación involucra costos fijos, debidos a la necesidad de adquirir información, al carácter incompleto que ella tiene y a los costos de patentes $u$ otras formas de proteger la propiedad intelectual. Por este motivo, el acceso a la tecnología es más limitado para las pequeñas empresas y éstas tienden a acumular con el tiempo desventajas competitivas dinámicas asociadas al menor aprendizaje por experiencia. En este contexto, los sectores productivos incluyen en todo momento empresas con muy diferentes conocimientos técnicos, con lo cual el concepto neoclásico de "firma representativa" pierde significado. Esta diferenciación interna de los sectores productivos es, por supuesto, esencial para entender los procesos de reorganización que resultan de choques competitivos, como aquéllos surgidos de las aperturas externas de las economías o de trastornos recesivos.

Las consideraciones expuestas tienen amplias implicaciones para las políticas públicas. Implican, en primer término, que los procesos tecnológicos se caracterizan por el predominio de cconomías de escala dinámicas, en medio de las cuales las ventajas comparativas son creadas, fruto de la propia experiencia productiva. Implican, además, que la pérdida de experiencia productiva puede generar efectos acumulativos en el tiempo, que terminan por destruir o rezagar considerablemente el conocimietito tecnologico. ${ }^{9}$ Aunque la presión competitiva elimina actitudes complacientes de las empresas y las obliga a estar al día en sus conocimientos. ${ }^{10}$ puede tener también efectos opuestos: en particular, si induce una baja en la producción de un sector o una empresa, puede originar efectos acumulativos en su capacidad competitiva e impedir que las empresas inviertan lo suficiente en su adaptación tecnológica. El predominio de las estrategias defensivas sobre las ofensivas durante los procesos de reestructuración productiva en América Latina y el Caribe (véase la sección II de este artículo) demuestra precisamente que la introducción de mayor competencia no siempre pone en marcha las formas de adaptación tecnológica con mayores potencialidades para la gencración de ventajas comparativas, de "competitividad sistémica", para emplear el término de Fernando Fajnzylber que ha venido utilizando extensamente la CEPAL en la última década. Todo cllo explica por qué no existe una clara asociación entre neutralidad de incentivos y cambio tecnológico. ${ }^{\text {Il }}$

Los factores expuestos justifican la intervención del Estado en la creación, adaptación y difusión de tecnología. Esta es, además, una de las pocas áreas donde los subsidios estatales (dentro de ciertos límites) están explícitamente aceptados por la Organización Mundial del Comercio y son, por lo tanto, consisten-

\footnotetext{
צ Véase, por ejemplo, el simple y elcgante modelo de Krugman (1990, cap. 7).

10 Esto significa, por to denás, que las firmas no maximizan ganancias si no están sobre su curva de posibilidades de producción, y que la presión competitiva las obliga a esıar sobre clla.

11 Sobre esta materia existe una amplia literatura. Véanse. por ejemplo, los trabajos recogidos $\mathrm{cn}$ Helleiner (1992).
} 
tes con el contexto actual de globalización. La protección de sectores productivos incipientes o en etapas de aprendizaje intensivo, ${ }^{12}$ así como la promoción de nuevos sectores exportadores con iguales caracteristicas, son los instrumentos alternativos, pero para aplicarlos se precisa una clara delimitación temporal de la protección o promoción, y una clara asociación entre ellas y el desempeño.

Dicho sea de paso, en la etapa de proteccionismo de la historia latinoamericana y caribeña no se cumplió con estos requisitos, por lo cual sus resultados en términos de avance de la productividad fueron claramente subóptimos. Tal posición, por lo demás, estuvo fitmemente arraigada en patrones de economía politica muy conocidos. Por estos motivos, sin descartar el uso de instrumentos de proteccion que cumplan los requisitos mencionados, los esfuerzos estatales deben estar orientados a apoyar el desarrollo de redes de innovación, impulsando la creación de nuevas instituciones y destinando recursos y generando incentivos para que se destinen recursos privados a sus actividades. Entre este tipo de instituciones se encuentran centros sectoriales o regionales de investigación tecnológica o de productividad, asociaciones universidad-industria, redes de asistencia técnica a pequeñas empresas urbanas y rurales, parques tecnológicos, fondos de capital de riesgo orientados a apoyar actividades tecnológicas, incubadoras de empresas, incentivos a las actividades de innovación dentro de las empresas o a los aportes privados a instituciones tecnológicas, etc. Todas ellas hacen ya parte del panorama latinoamericano y caribeño, pero su desarrollo no ha alcanzado todavía un nivel deseado (Alcorta y Peres, 1998).

\section{Las complementarledades estratégicas}

No existe ninguna idea más central en la teoría clásica del desarrollo económico -ni en la teoría de la localización, que sirve de base a las teorías de desarrollo regional y urbano- que el concepto de la complementariedad entre las decisiones de inversión o de encadenamientos (hacia adelante o hacia atrás) que ellas generan, para utilizar el clásico concepto de Hirschman (1958). Cuando ello coincide con la presencia de economías de escala en la producción se generan, en ta terminología moderna, "complementariedades estraté-

12 Tarnbién existe, sobre la base de los argumentos mencionados, una justificación para la graduatidad en los procesos de apertura económica. Sin embargo, tal anotación sólo tiene hoy un interes histótico. gicas" que dan lugar a procesos de aglomeración (Krugman, 1995).13

Los fenómenos de aglomeración están en la esencia misma de los debates históricos sobre desarrollo económico. En este sentido, la observación de que estructuras económicas distintas dan lugar a distintos ritmos de desarrollo a través de la fortaleza o debilidad de las economías de aglomeración que generan, así como a desequilibrios particulares asociados a la naturaleza de dichas estructuras y a la forma como los desequilibrios se van resolviendo, está en la esencia misma de las teorías estructuralistas de desarrollo. $\mathrm{La}$ defensa clásica de la industrialización por parte de la CEPAl es parte de esta tradición. En este contexto, las variables agregadas que analizan otras teorlas de crecimiento pueden verse más como efectos que como causas de esta dinámica estructural. Por ejemplo, los ritmos de cambio técnico pueden ser enteramente diferentes en distintas dinámicas estructurales, las funciones de inversión pueden verse igualmente afectadas $e$ incluso igual aseveración puede hacerse sobre los ritmos de desarrollo de capital humano que originan.

Este no es, por supuesto, el lugar para analizar los costos y beneficios de la estrategia clásica de industrialización, ${ }^{14}$ sino el de examinar la relevancia de estas complementariedades estratégicas en la etapa actual de desarrollo de la región. Aunque la nueva revolución tecnológica y la globalización han erosionado algunos de los fundamentos de estos procesos de aglomeración, la implicación más importante de ellos es que la "competítividad sistémica" (o su ausencia) es el resultado de sinergias y externalidades que se gene. ran entre las empresas pertenecientes a determinadas cadenas productivas, y de la forma como dichas cadenas se encuadran en el conjunto de la economía. De ahí se deriva, por ejemplo, la importancia de analizar los encadenamientos que generan los complejos productivos en torno a los recursos naturales (Ramos, 1998) o la forma como los procesos de integración en marcha vienen generando nuevos encadenamientos productivos entre sectores industriales de distintos países (en la industria automotriz, por ejemplo). Otra implicación significativa en la etapa actual de la región

\footnotetext{
${ }_{13}^{3}$ Los costos de transporte $(y$, en general, los costos de transacción asociados a la distancia) desempeñan un papel algo más complejo. Pueden contribuir a la aglomeración pero, si son suficientemente elevados, pueden generar el fenómeno opuesto, como lo señala la larga Iradición de la teoría de la localización.

It Mis propias contribuciones a este debate han sido recogidas en la introducción del trabajo de Cárdenas, Ocampo y Thorp, eds. (1998),
} 
es la conveniencia de desarrollar nuevos sistemas de promocion de exportaciones, en los cuales se incentive la acción conjunta en mercados de destino de empresas afines de una misma región o país. Igualmente, este análisis señala la importancia de fomentar mecanismos que faciliten el intercambio de información entre empresarios de un mismo sector o cadena productiva, especialmente sobre posibles decisiones de inversion, y que propicien la realización de alianzas estratégicas entre ellas o induzcan inversiones complementarias, así como de desarrollar análisis regulares de competitividad de sectores productivos específicos con los empresarios correspondientes, e incentivar el desarrollo de grupos de investigación que se especialicen en dichos análisis. La conformación de parques industriales es otra estrategia de esa índole, que además tiene especial trascendencia para la planificación regional y local moderna.

La necesidad de tener en cuenta las complementariedades estratégicas en la nueva etapa de desarrollo ha sido subrayada por la CEPAL a lo largo de los años noventa (por ejemplo en CEPAL, 1990, 1996 y 1998a). Estas propuestas significan, en particular, que la nueva estrategia de desarrollo no elimina la conveniencia de contar con polfticas sectoriales de un nuevo tipo (o, como se dice a veces, en forma más restrictiva, con una "política industrial"). La experiencia que se viene acumulando en la región indica que dichas políticas deben surgir de esfuerzos conjuntos entre el sector público y el sector privado, Jo cual exige una transformacion profunda de las instituciones públicas y privadas heredadas de la fase anterior del desarrollo. El objetivo fundamental de dichos ejercicios debe ser elaborar "visiones" conjuntas y concertar la forma como se deben "especificar", para sectores particulares, mecanismos de apoyo que, a nivel global, deben ser concebidos como instrumentos esencialmente horizontales (desarrollo tecnológico, formación técnica, promoción de exportaciones, infraestructura, crédito, etc.), pero que para ser efectivos necesitan "detallarse" (por ejemplo, señalando la naturaleza de las instituciones que van a apoyar el desarrollo tecnologico del sector, los requerímientos colectivos de éste en materia de calificaciones laborales, la forma en que se van a garantizar los recursos financieros necesarios para su expansión, etc.).

Es evidente que, aun si pueden justificarse teoricamente, no existen hoy en la región bases para promover formas más agresivas de planeación sectorial, como las que en su momento desarrollaron los pafses asiáti$\cos$. Sin embargo, es importante resaltar que el hecho de que con frecuencia se oculten decisiones sectoriales estratégicas no quiere decir que dichas decisiones no existan. De hecho, la apertura económica fue una clara decisión esıratégica, más o menos explícita: la de promover en mayor medida a los sectores que hacen uso más intensivo de recursos naturales y eliminar ramas industriales ineficientes. En presencia de recursos públicos escasos, las decisiones de asignar fondos a algunos sectores para sus actividades tecnológicas o para la promoción de sus exportaciones involucra también decisiones estratégicas (fomentar estos y no otros sectores, 0 estos más que otros sectores). Por este motivo, más que ocultar tales decisiones, es deseable hacerlas explícitas a través de "visiones conjuntas" de los sectores público y privado, incluido el laboral.

\section{Regulación de los servicios de infraestructura}

La privatización creciente de empresas de servicios públicos y la apertura de espacios para la participación privada en nuevos proyectos de infraestructura han ofrecido oportunidades (de eliminar ineficiencias considerables en los sectores correspondientes y de atraer nuevos capitales, destinando recursos públicos escasos a otros sectores), pero han planteado también innumerables retos. Debido a importantes economías de escala y a otro tipo de dificultades tecnológicas (que han venido siendo superadas en algunos casos), los sectores de infraestructura se caracterizan casi invariablemente por estructuras de competencia imperfecta e incluso en muchos casos constituyen monopolios naturales (especialmente a nivel regional y local, pero también nacional). Además, dado su carácter de servicios no transables internacionalmente, la competencia externa no desempeña, en este caso, el mismo papel regulador que en los sectores productores de bienes.

El primer reto que surge en este contexto es la necesidad de establecer marcos regulatorios apropiados para garantizar que las tarifas se aproximen a soluciones competitivas y en especial que la mayor eficiencia que se puede derivar de los procesos de privatización o de la mayor competencia se traslade efectivamente a los consumidores. Los problemas regulatorios de los períodos de transición son extremadamente complejos, especialmente porque involucran la tarea de crear mercados (por ejemplo, bolsas de energía) y no sólo de regular los existentes. Además, los agentes se encuentran en diferentes etapas de asimilación de los nuevos marcos de política y tienen infornación aún más asimétrica que la que se observa en mercados maduros. Vale la pena resaltar la importancia decisiva 
de poner en marcha, en este contexto, no sólo entes reguladores altamente calificados, sino superintendencias que vigilen la aplicación de sus decisiones y se introduzcan en una de las áreas más olvidadas del viejo marco de política: la defensa del consumidor.

El segundo desafío es el manejo adecuado de las garantías públicas. Este problema tiene particular trascendencia en los nuevos proyectos de infraestructura, donde el sector privado sólo participa si el Estado está dispuesto a otorgar garantías contra riesgos que los agentes privados consideran que no pueden asumir (riesgos regulatorios y de fuerza mayor, pero también de ingresos, de liquidez, o de incremento de costos más allá de lo previsible). La asunción de estos riesgos por parte del Estado genera contingencias fiscales considerables. Por este motivo es necesario, en primer término, diseñar esquemas de participación privada que minimicen el otorgamiento de tales garantías, limitando los riesgos asumidos por el Estado a aquellos que no son asegurables en el mercado y que el sector privado efectivamente no puede controlar. Por otra parte, los riesgos que asuma el sector público deben ser valorados. Las estimaciones correspondientes, aunque imperfectas, deben tomarse en cuenta en el Jebate anual del presupuesto e incluso conviene que el valor equivalente a la prima anual de los "seguros" que ha otorgado el Estado sea explícitamente presupuestado. Ello permite, además, comparar adecuadamente esta forma de financiamiento con opciones que involucren una mayor participación de recursos públicos, como los proyectos financiados por el sector público pero administrados privadamente. ${ }^{15}$

Los problemas que enfrentan la regulacion y el otorgamiento de garantías nos conducen a un tercer reto: la necesidad de evitar prácticas de captación de rentas que pueden ser tanto o más aberrantes que en el esquema público anterior. En esta materia, es escncial adoptar mecanismos de control social que eviten la "captura" de los entes regulatorios por los regula. dos. Igualmente, es necesario estimar y discutir públicamente, en torno al debate del presupuesto, las prácticas de otorgamiento y los montos de las garantías concedidas por las instituciones estatales, así como establecer reglas claras que eliminen las garantías "implicitas" (es decir, la percepción de que los proyectos privados que fracasen serán rescatados por el scctor público), las cuales pueden dar lugar a serios problemas de "riesgo moral".

\section{V}

\section{Equidad y política social}

\section{El reto de la equidad}

Los problemas de equidad característicos de la región están arraigados en estructuras distributivas altamente desiguales, en gran medida heredadas de etapas anteriores de desarrollo. Como lo señala un reciente informe de la CEPAL (1998d), ellas reflejan la conjunción de factores educativos, ocupacionales, patrimoniales y demográficos. La fuerte desigualdad en los años de estudio que han cursado las personas ocupadas ha sido el factor más destacado en los debates recientes. La falta de equidad está también relacionada con la desigualdad en la distribución del patrimonio, aún más concentrada que la desigualdad en la educación (véase, sobre este aspecto, Birdsall y Londoño, 1997). Asimismo, el número de personas ocupadas por hogar es menor en los hogares de ingresos bajos y los puestos de trabajo a los cuales acceden son de menor calidad. Por último, las familias pobres tienen más hijos dependientes.
Detrás de los patrones nacionales subyacen, además, considerables disparidades regionales, de tal forma que los problemas de pobreza están relativamente más concentrados en aquellas regiones que enfrentan mayores dificultades para integrarse al proceso de desarrollo. Aunque la migración genera en el largo plazo una tendencia a la nivelación de los ingresos regionales, por períodos amplios puede tener también efectos adversos, ya que es selectiva, es decir, tiende a extraer de las regiones atrasadas a las personas con mayor capital humano. Lo mismo sucede con la movilidad de capitales, que aunque puede tener efectos niveladores en el largo plazo, durante períodos cxtensos puede generar, a través de las economías de aglomeración, una atracción fuerte hacia los centros de desartollo más dinámicos.

\footnotetext{
is Véanse, sobre estos temas, los trabajos incluidos en Irwin, Klein, Perry y Thobani (eds.) (1997) y cEPaL (1998b, cap. IX).
} 
A partir del trabajo de Morley (1994 y 1995), diversos estudios han confirmado que la pobreza tiende a reducirse con el crecimiento económico. El incremento de la pobreza durante los años ochenta y su reducción en los noventa obedecen a este patrón. No obstante, éste es estrictamente válido sólo para la pobreza urbana, on tanto que la pobreza y, sobre todo, la indigencia rurales tienen un comportamiento mucho más inercial, característico de los fenómenos de "pobreza dura" (Ocampo, 1998b). Por otra parte, los datos confurman ampliamente el deterioro en la distribución del ingreso que ha tenido lugar a lo largo de las últimas décadas en varios países de la región. ${ }^{16} \mathrm{El}$ análisis de este proceso ha sido objeto de una activa polémica en la que están en juego fundamentalmente dos tesis alternativas. La primera postula la existencia de una asimetría en el comportamiento de los ingresos de los más pobres a lo largo de ciclos agudos de crecimiento, como los que ha experimentado la economía latinoamericana en las últimas décadas; tienden a reducirse más en los períodos de crisis de lo que logran recuperarse en los períodos de auge. Esto refleja probablemente la pérdida de capital humano (experiencia) durante los períodos de crisis, así como las asimetrías en el comportamiento del mercado laboral (los recortes de puestos de trabajo durante las crisis no van seguidos de aumentos similares en los periodos de auge, los cesantes pierden conexiones laborales que nunca recuperan, etc.). La segunda tesis estima que la liberalización cconómica y la globalización han tendido a deteriorar la distribuciớn del ingreso.

Uno de los autores que ha recalcado más esta última visión es Albert Berry. Este autor ha mostrado en varios trabajos que hay pruebas en el último cuarto de siglo de que la introducción de medidas de liberalización cconómica ha estado asociada con deterioros, a veces sustanciales, en la distribución del ingreso (Berry, 1998). ${ }^{17} \mathrm{El}$ trabajo comparativo de Robbins (1996) indica también que los procesos de apertura comercial tendieron a generar una mayor desigualdad en la distribución de los ingresos laborales. Los aumentos en las disparidades de ingresos entre trabajadores más y menos calificados durante los años noventa (CEPAL, 1997) y el escaso dinamismo de la creación de empleo

to Véase un análisis mís extenso de estas tendencias en Altimir (1997), Berry (1998), Morley (1994 y 1995), BaD (1997) y CRPAi (1997).

17 La información de ese autor proviente de las experiencias de Argentina, Chile, Colombia, México, la República Dominicuna y Uruguay, en tanto que Costa Rica es una excepción. formal, a los cuales hicimos alusión en la sección II, pueden ser también confirmaciones en igual sentido. Esta desigualdad creciente de las remuneraciones por niveles de calificación no parece ser exclusiva de la región. De hecho, un reciente informe de la UNCTAD (1997) indica que puede ser un hecho casi universal, ya que ha afectado a varios países industrializados y algunas cconomías de rápido crecimiento del AsiaPacífico y ha generado, en particular, una presión severa sobre las clases medias de muchos países.

Existen varias explicaciones posibles de estas tendencias. La más sugestiva es la de Rodrik (1997), según la cual la globalización acentúa la asimetría entre los factores que pueden cruzar con mayor facilidad las fronteras nacionalos -el capital y la mano de obra más calificada $-\mathrm{y}$ aquellos que no pueden hacerlo: la mano de obra menos calificada. La posibilidad de relocalizar la producción hace que la demanda laboral se torne más elástica en todos los países, reduciendo la capacidad de negociación de los trabajadores y aumentando la inestabilidad de sus ingresos frente a perturbaciones de la demanda. Por otra parte, según Berry (1998), la expljcación puede estar asociada a las economías de cscala que caracterizan el comercio y financiamiento internacionales, las que se reflejan en la mayor participación en estas actividades de las firmas más grandes dentro de cada sector. Tales firmas son, a su vez, las que hacen uso intensivo de capital y/o mano de obra más calificada. Se ha sugerido también que las mayores transferencias de tecnología que genera el propio comercio, incluidas aquellas incorporadas en la maquinaria y $\mathrm{cl}$ equipo importados, pueden llevar a que países en desarrollo inmersos en procesos de internacionalización adopten tecnologías que requiercn mano de obra calificada y hath sido diseñadas en función de las necesidades de los países industrializados (Robbins, 1996). Las estrategias de reestructuración productiva de las empresas latinoamericanas frente a la apertura y la globalización han tenido efectos desfavorables sobre la creación de empleo, según lo señalamos en secciones anteriores.

En el caso latinoamericano, puede haber otras explicaciones de este fenómeno. Una de ellas es que el proceso de liberalización tuvo lugar después de una década de debilitamiento del gasto social. La mayor demanda laboral de mano de obra unás calificada enfrentó, por lo tanto, una oferta inelástica de tales trabajadores. Por lo demás, durante el proceso mismo de liberalización, no hubo esfuerzos claros por acoplar la demanda y la oferta de calificaciones. Otra explicación señalaría que la política macroeconómica que ha acom- 
pañado el proceso de reforma, en especial la tendencia a la revaluación de los tipos de cambio y la apertura de las cuentas de capitales, originó patrones de crecimiento en los cuales las importaciones crecieron más que las exportaciones, generando además un sesgo en contra de los sectores con mayor contenido de mano de obra. El manejo macroeconómico se ha caracterizado, además, por fuertes ciclos de "pare y siga" asociados al comportamiento de los flujos de capital, to cual ha obstaculizado la generación de puestos de trabajo más estables.

\section{Los espacios de la política social}

Estas consideraciones indican que, sobre una estructura distributiva ya muy desigual, la crisis de la deuda, la liberalización y la globalización (a las que las distintas explicaciones atribuyen peso diferente) han acrecentado enormemente el reto en materia de equjdad. Uno de los grandes desafíos que enfrenta la región es, por lo tanto, demostrar que el nuevo modelo de desarrollo es compatible con la corrección gradual de las grandes desigualdades sociales existentes. De no lograrse este objetivo, podrían deteriorarse las bases políticas de las reformas, que han sido sólidas hasta ahora, en gran medida porque el retomo a la estabilidad macroeconómica ha sido visto como positivo por el conjunto de la población. $Y$ lo que es igualmente grave, podrían surgir tensiones sociales que dificultaran la gobernabilidad y erosionaran las bases de los consensos políticos que han permitido el fortalecimiento de la democracia en la región, sin duda otro de los grandes logros de los últimos años. A más largo plazo, las secuelas de las desigualdades y la pobreza podrían minar las bases de la competitividad sistémica, sobre las cuales descansan las posibilidades de desarroIlo en un contexto internacional cada vez más abierto.

La experiencia internacional muestra resultados sorprendentes en el manejo de los riesgos sociales que trae consigo la globalización. El estudio de Rodrik (1997) indica que la mayor apertura de las economías ha estado compensada en el pasado por una mayor protección social del Estado a la población. Lo anterior se ha reflejado en una relación positiva entre el grado de apertura y el tamaño del Estado. Según el autor citado, ésta es válida, tanto para la OCDE como para una muestra amplia de 115 países, lo cual parecería indicar que la tensión distributiva generada por los procesos de apertura se abordó en el pasado intercambiando liberalización económica por mayor protección del Estado a través de una política social más activa.

El gasto social es, sin duda, el componente más importante a través del cual el Estado influye en la distribución del ingreso. Existe, en efecto, corroboración amplia de que el efecto del gasto social sobre la distribución secundaria del ingreso es significativo. La información disponible para América Latina sobre esta materia indica que, en términos absolutos, los sectores de mayores ingresos se benefician tnás del gasto social. Sin embargo, como proporción de los ingresos de cada estrato, los subsidios que se canalizan a través de dicho gasto son mayores para los sectores más pobres de la población. Este patrón global es el resultado de los impactos distributivos muy diferentes de distintos tipos de gastos. La focalización hacia los pobres (es decir, la proporcion del gasto que se destina a los pobres en relación con la proporción de la población en estado de pubreza) es elevada para los gastos en salud, educación primaria y, en menor medida, educa ción secundaria. Por el contrario, los gastos en seguridad social y en educación superior tienen una tenden. cia generalmente regresiva. Los gastos en vivienda se encuentran en una situación intermedia, ya que benefician especialmente a estratos medios de la distribución del ingreso. Estos resultados indican que existe un amplio margen para mejorar la distribución del ingreso a través del gasto social, pero también para mejorar la focalización de este último, como lo señala un reciente estudio de la CEPAL. La forma en que esto se financie no es, por supuesto, irrelevante: un financiamiento con impuestos directos tiende a ser más pro* gresivo que un financiamiento con impuestos indirectos $y$, lo que es igualmente importante, un financiamiento inadecuado, que se traduzca en aceleración de la inflación, puede contramestar los efectos distributivos favorables (CEPAL, 1998b, cap. VI).

Existe, por lo tanto, un margen apreciable para conjugar la liberalización económica con una política social más activa, como parecen reflejarlo, por lo demás, los patrones internacionales tradicionales. Es necesario entonces dedicar esfuerzos a reorientar el gasto público hacia el sector social - como ya se ha comenzado a hacer en América Latina en los años noventa-, así como para focalizar el gasto social y maximizar sus efectos distributivos favorables. Algunos países pueden también inclinarse por una expansión adicional del gasto social financiada con mayores ingresos tributarios. Esta fue, de hecho, la alternativa por la cual optó el gobierno chileno a comienzos de 
la década actual, sin que con ello se perjudicasen la inversión real ni el crecimiento económico. Es también la opción que ha seguido Colombia en los años noventa (el país de la región que más ha aumentado el gasto social en esta década), aunque en este caso ha habido un desfinanciamiento parcial y, por lo tanto, necesidades de ajuste fiscal que no se han atendido por completo. En estos casos, el impacto distributivo neto dependerá, según hemos visto, de la forma de financiamiento.

En el largo plazo, la mayor inversión en capital humano pernite también incidir sobre uno de los factores estructurales de la distribución del ingreso. Los estudios existentes muestran, en efecto, que una mayor asignación de recursos a la educación, que permita mejorar la distribución de capital humano en la sociedad, puede tener efectos sobre la distribución del ingreso muy superiores a aquellos que se han estimado en los estudios de incidencia distributiva de corto plazo (por ejemplo, BID, 1997, pp, 82-83). Como nota de cautela, cabe resaltar que existe también corroboración de que un gran esfuerzo en educación tenderá a reflejarse en retornos decrecientes a la inversión en ella. Además, como en un proceso de crecimiento la economía demanda mayores niveles educativos para un mismo puesto de trabajo, hay una "devaluación" de la educación en el mercado laboral y, por lo tanto, de la generación de ingresos.

Esto es lo que indica un reciente informe de la CEPAL (1998d). Este estudio comprueba que la expansión de los años de estudio registrada en las últimas décadas en América Latina (en un promedio de tres años y medio, si se comparan los años de estudio de los jovenes de 20 a 24 años con los de sus padres), no ha logrado mejorar las oportunidades de los jóvenes provenientes de estratos socjales pobres. En efecto, el informe encuentra que sólo la mitad de los jovenes urbanos y una cuarta parte de los rurales han mejorado su nivel educativo en relación con el de sus padres más de lo que han aumentado las exigencias del mercado de trabajo, de tal forma que tienen efectivamente mejores oportunidades ocupacionales que sus progenitores. Esto concuerda con los resultados de encuestas que señalan que sólo la mitad de los jóvenes latinoamericanos consideran que tienen mejores oportunidades que sus padres.

En igual sentido, el informe citado muestra que los esfuerzos por ampliar la cobertura educativa no se han traducido en una disminución de la distancia que separa a los jovenes de distintos estratos sociales. En particular, si se tiene en cuenta el capital educativo de los padres, los logros educativos de los jovenes lati- noamericanos no han mejorado (o sólo lo han hecho marginalmente) en los últimos 15 años. ${ }^{18}$ Además, se advierte que los jóvenes con el mismo nivel educativo y las mismas ocupaciones ganan entre 30 y $40 \%$ más que sus congéneres si provienen de hogares cuyos padres tienen mayores ingresos. Esto muestra que la expansión de la educación en un contexto de desigualdad social no siempre se traduce en igualdad de oportunidades. Aun en Chile, donde una mejor distribucion de las oportunidades educativas ha coincidido con una economía muy dinámica y un ritmo positivo de creación de empleo, todo lo cual se ha reflejado en una reducción sensible de la pobreza, la distribución del ingreso no ha mostrado hasta ahora mejoría.

Por este motivo, si bien mayores niveles de educación y una mejor distribución de las oportunidades educativas son esenciales, no bastan para mejorar la distribución del ingreso. Es necesario aplicar simultáneamente políticas en las áreas educativa, ocupacional, patrimonial y demográfica, y dirigir acciones particularmente agresivas en todos estos frentes hacia las zonas rurales y hacia regiones atrasadas o aquellas que han tendido a quedarse rezagadas con los cambios en los patrones de desarrollo.

En el caso de la educación, las reformas deben tender a que los jóvenes completen la educación secundaria, con una calidad y a una edad adecuadas, y a reducir la gigantesca brecha que subsiste en todos los países, entre las oportunidades educativas de la ciudad y del campo. Debe apuntarse además a compensar las desventajas con que inician sus estudios los niños provenientes de los hogares más pobres, ampliando la cobertura de la educación preescolar, reteniendo a los jóvenes más tiempo dentro del sistema escolar y manejando adecuadamente los problemas del embarazo adolescente, que afectan las oportunidades educativas de la madre y de sus hijos. Como to señala una amplia literatura sobre el tema, los avances educativos (y los esfuerzos especiales con tal propósito) deben traducirse, además, en una planificación familiar consciente, que reduzca los problemas de alta dependencia demográfica que caracteriza a los hogares más pobres.

En materia ocupacional, los esfuerzos más importantes deben estar dirigidos a la capacitación para el

\footnotetext{
18 Por ejemplo, a comienzos de los alios ochenta, la proporción de jóvenes cuyos padres tenian enire seis y nueve anjos de educación que llegaban a tener educación secundaria completa oscilaba entre 33 y $43 \%$ en los paises analizados en el estudio; a mediados de los noventa, dichas proporciones permanecían prácticamente inmodificadas: entre 36 y $46 \%$,
} 
trabajo y a desarrollar redes integrales de apoyo (capacitación empresarial, transferencia de tecnología, crédito, nuevos canales de comercialización) a las empresas pequeñas y microempresas urbanas y rurales, donde laboran las personas de menores ingresos. Aunque la globalizacion exige, sin duda, que se flexibilicen algunas normas laborales, es evidente que la solución a los problemas estructurales de empleo de la región no está en una liberalización radical de dicho mercado. Más aún, la mayor flexibilidad laboral que se acuerde politicamente en cada país debe ir acompañada por mayor protección social en otros campos. En particular, hay claras pruebas en la region de que las políticas más activas de salario mínimo (obviamente, dentro de los límites de su sostenibilidad macroeconómica) están asociadas a mayores reducciones de los sectores en situación de pobreza en los años noventa (Morley, 1997). Los sistemas de información sobre oportunidades de emplco y de calificación para el trabajo, especialmente los orientados a quienes han perdido sus puestos de trabajo, se encuentran todavía muy atrasados.

Por último, conviene resaltar la importancia de orientar la discusión hacia las oportunidades para mejorar la distribución de activos, como las políticas dirigidas a pequeños productores y las de vivicnda social. En este campo, uno de los aspectos que debe recibir especial atención son los mecanismos que permitan redistribuir activos sin gencrar distorsiones en la actividad económica, como la creación o perfeccionamiento de instituciones para canalizar crédito a pequeñas empresas o microempresas sin distorsionar el mercado, o los nuevos esquemas de reforma agraria que utilizan activamente el mercado de tierras.

\section{La politica social y las reformas de segunda generación}

Los esfuerzos por aumentar y focalizar el gasto social en la región deben complementarse con una importante reorganización del sector, que haga más eficiente y efectiva la oferta de servicios sociales. Este es uno de los temas centrales de las llamadas reformas de segunda generación, cuyo propósito esencial es elevar la eficiencia de los mercados e incorporar criterios de racionalidad microeconómica en la provisión de aquellos servicios que han carecido de cllos.

En el tema de los servicios sociales se ha hecho hincapié en la introducción de elementos de competencia en su provisión (creación de cuasimercados), con la participación de agentes privados y con cambios en las modalidades de apoyo estatal (desde los tradicionales subsidios a la oferta de dichos servicios hasta subsidios a la demanda). En forma paralela y complementaria se ha procurado descentralizar la prestación de aquellos servicios que continúan a cargo det Estado, crear nuevos esquemas de gestión pública orientada a resultados, dar autonomía efectiva a las entidades puiblicas prestadoras de servicios y establecer mecanismos de participación ciudadana para el control de la gestión pública. Unos y otros componentes de esta reorganización, pero especialmente los primeros, están orientados a enfrentar las fallas de gobierno que se han hecho evidentes en el pasado en la provisión de servicios sociales y que se reflejan en la ineficiencia y baja calidad de los servicios prestados por el Estado.

La experiencia muestra que cl sector privado responde en forma dinámica a los incentivos que se le proporcionan. Sin embargo, indica igualmente que dicha participación cstá sujeta a fallas de mercado, tanto de carácter tradicional, relacionadas con economías de escala, como aquetlas asociadas a problemas de información, resaltadas por la literatura más reciente, que dan lugar a fenómenos de competencia imperfecta, selección adversa y riesgos morales (Ocampo, 1996). En economías con fuertes disparidades distributivas, el problema más importante es la atracción natural, generada por cl mercado, a que el sector privado oriente su oferta - tanto en cantidad como, especialmente, cn calidad - a los sectores de mayores ingresos. Este problema no se soluciona necesariamente con un esquema de subsidios a la demanda y exige, por lo tanto, que el Estado diseñe instrumentos para aumentar la oferta dirigida a los sectores de menores ingresos. Como la oferta pública ha sido en muchos casos igualmente incapaz de llegar a ciertos sectores de la población (por ejemplo, en los programas de vivienda popular), es preciso promover la participación de nuevos agentes, que generalmente tienen un carácter soljdario o comunitario.

Las dificultades anteriores se acentúan cuando el diseño de los esquemas de participación privada no incluye claros principios de solidaridad, como lo ilustra el sistema privado de salud en Chile (CEPAL, 1998b, cap. VII), En este caso, la sclección adversa - tanto por estratos socioeconómicos como por los riesgos de salud asociados a la edad de la población cubiertapuede ser muy marcada. Sin embargo, la introducción de elementos de solidaridad no soluciona automáticamente el problcma. Así, por ejemplo, la reforma de la salud en Colombia estableció un sistema en el cual los beneficios son totalmente independientes del monto de la cotización, pero la respuesta del sector privado ante 
los estratos más pobres ha sido igualmente frustrante. La respuesta privada puede ser, además, geograficamente desequilibrada: responde mejor en ciudades grandes, pero es insuficiente en pequeñas poblaciones o en el sector rural, donde - debido a mínimas economías de escala - puede haber "monopolios naturales" en muchos servicios, bajo condiciones en las cuales, además, su provisión no es rentable.

En los casos en que la oferta responde inadecuadamente -en términos de cantidad o calidad- a los incentivos generados por los subsidios a la demanda, puede ser conveniente discñar fórmulas intermedias, que podrían denominarse "subsidios a la oferta con criterios de demanda", los cuales permitirían actuar sobre la oferta, incluida la calidad de los servicios, y obtener al mismo tiempo los beneficios tradicionales de los subsidios a la demanda en términos de focalización de los beneficiarios. Los esquemas intermedios consisten en la contratacion de determinados agentes para proporcionar los servicios a un grupo específico de la población, a través de un sistema de concurso competitivo, o de la promoción de organizaciones comunitarias o solidarias con el propósito explícito de otorgarles la administración de los servicios correspondientes. Este puede ser también el esquema apropiado para promover la creación de nuevos servicios o la mejoría en la calidad de los existentes (por ejemplo, para elcvar la calidad del sistema educativo, como viene haciéndose en Chile).

Por otra parte, los problemas de información son mucho más graves en los mercados de servicios que en los de bienes. En particular, hay insalvables asime- trías en la información entre quienes prestan servicios muy especializados y quienes los reciben (entre médico y paciente, en particular, en el caso de la salud, pero fenómenos similares se dan también en la educación). Por este motivo, el desarrollo de cuasimercados para la prestación de servicios sociales exige la creación de esquemas mínimos de información e instrumentos muy desarrollados de protección a los usuarios.

Las reformas que se adopten en este marco de ben ser pragmáticas e involucrar, por lo tantn, un importante componente de gradualismo y aprendizaje por experiencia. Más aún, debe tenerse presente que los nuevos esquemas de participación privada no son en todos los sectores un sustiuto de la oferta pública de servicios. Por este motivo, los esfuerzos por mejorar la oferta pública a través de la descentralización, la autonomía de las entidades prestadoras de servicios, la introducción de criterios de evaluación de la gestión pública y el control ciudadano son, sin duda, elementos centrales de cualquier reforma en materia de servicios sociales.

Por último, conviene poner de relieve que uno de los grandes hitos de las reformas en los servicios sociales debe ser el diseño de sistemas apropiados de regulación, información y control de calidad de los scrvicios prestados. Esto es particularmente importante cuando las características especializadas de los servicios no garantizan la transparencia de la información en la que se basan los consumidores para elegir a sus proveedores. Este es un tema todavía incipiente, al que deberán dedicarse esfuerzos considerables en los próximos años.

\section{Bibliografia}

Alcorta, L. y W. Peres (1998): Innovation systems and technological specialization in Latin America and the Caribbean, Research Policy, vol. 26, Ansterdam, Paises Bajos, North-Holland.

Altimir, O. (1997): Desigualdad, empleo y pobreza en América Latinat efectos del ajuste y del cambio en el estilo de desaIrolto, Desarrollo económico, vol. 37, N¹45, Buenos Aires. Inslituto de Desarrollo Económico y Social ([DES), abril-junio.

Akyid\%, Y, y C. Gore (1994): The Investment-Profits Nexus in East Asian Industrializarion, Discussion papers, ND 91, Ginebra, Conferencia de las Naciones Unidas sobrc Comercio y Desarollo (UNCTAD).

Bacha, E. y C. F. Díaz-Alejandro (1982); International Financial Imermediction: A Long and Tropicul View, Essays in international finance, $\mathrm{N}^{\circ}$ 147, Princeton, New Jersey, Princeton Universily, Department of Economics, Intemational Finance Section, mayo.
Baro, R. J. (1997): Determinans of Economic Growh: A Crosscountry Empirical Study, Cambridge, Massachusetts, MIT Press.

Barro, R. J. y X. Sala-i-Martin (1995): Economic (Krowth, Nueva York, McGraw Hill.

Benavente, J. M., G. Crespi, J. Katz y G. Stumpo (1997): Nuevors problemas y oportunidades para el desarrollo industrial de Antérica Latina, Desarrollo productivo, $\mathrm{N}^{\circ} 31$, Santiago de Chile, Comisión Econónica para América Latina y el Caribe (CEPAL).

Berty, A. (1998): Confronting the incone distribution threat in Latin America, A. Berry (ed.), Poverty, Economic Refornt, and incone Distribution in Latin America, Boulder, Colorado, Lynne Riemmer.

BID (Banco Interamericano de Desarrollo) (1997): Progreso económico y social en América Latina. Informe 1997, Washinglon, D.C. 
Birdsall, N. y J. L. Londofio (1997): Asset Inequality Does Mafter: Lessons from Latin América, Working Paper $\mathrm{N}^{\circ} 344$, Washington D.C., BJD.

Cárdenas, E., J. A. Ocampo y R. Thorp (eds.) (1998): Industrialization and the State in Latin America: The Black Legend and the Post War Years, en prensa.

CEPAL (1990): Transformeción productiva con equidad, LCG.160L-P, Santiago de Chile. Publicación de las Naciones Unidas, $\mathrm{N}^{\circ}$ de venta S.90.Jl.G.6.

(1994); El regiotatismo abierto en America Latita y el Caribe: La integración económica al servicio de la transfor. mación productiva con equidad, LC/G.1801/Rev, I+P, Santiago de Chile. Publicación de las Nacions Unidas, $N^{*}$ de venta S94.II.G.3.

(1996): Fortulecer el desarrotlo. Interacciones entre macro y microeconomia, LC/G. 1898/Rev.1-P, Santiago de Chile Publicación de las Naciones Unidas, $N^{\circ}$ de venta S.96.II.G.2. (1997): La brecha de la equidad: Anérica Latina, el Ca. ribe y la Cumbre Sacial, LC/G.1954/Rev. I-P, Santiago de Chile. Publicacjón de las Naciones Unidas, $\mathrm{N}^{*}$ de venta S.97.II.G.11.

(1998a): América Latina y el Curibe: Politicas para mejorar la inserción en la economia mundial, Santiogo de Chjle, Fondo de Cultura Econórnica (FCE).

(1998b): El pacto fiscal. Forzalezar, debilidades, deraflos. LC/G.2024, Santiago de Chile, abril.

(1998c): Inpucto de la crisis asiútica en América Latina LC/G.2024, Santiago de Chile.

(1998d): Panorama sivial de América Latina 1997. LC/G.1982-P, Santiago de Chile. Publicación de las Naciones Unidas, $\mathrm{N}^{\circ}$ de venta $\$ .98 . I I . G .3$.

(1998e): La invernión extranjesa en Antéricu Latima y el Caribe: Informe 1997, LC/G. 1958-P, Santiago de Chile. Publicación de las Naciones Unidas, $N^{\circ}$ de venta S.97.Jl.G.14.

Fajnzylber. F. (1990): Industrialización en Anérica Latina: de la "caja negra" "l "casilleso vacios", Cundemos de la CEPAL, No 60, LC/G.1534/Rev.1.P, Santiago de Chile, CEPAL

Ffrench-Davis, R. (en prensa): Reforwing the Reforms in Latin America: Macroeconomics, Trade, Finance, Londres, Macmillan.

Ffrench-Davis, R. y H. Reisen (comps.) (1997); Ftujos de capital e inversión producfiva. Lecciones pura Antérica Latina, Santiago de Chile, CEPAL/Organización de Cooperación y Desá rrollo Económices (OCDE).

Gavin, M., R. Hausmann y E. Talvi (1997): Savings behaviour in Latin America: Overview and policy issues, R. Hausmann y H. Reisen (eds.), Promoting Savings in Latin America, París. OCDE/BID.

Held, $G_{r}$ y A. Uthoff (1995); Indicators and Determinans of Savings for Latin America and the Caribbean, Working papers, $N^{\circ} 25$, Santiago de Chile, CEPAL.

Helleiner, G. K. (ed.) (1992): Trade Poltcy, Industrialization, and Development: New Perspectives, Onford, Clarendon Press.

Hirschman, A. O. (1958): The Strusegy of Econsmic Development. New Haven: Yale University Press.

Irwin, T. M. Klein, G. Perry y M. Thobani (eds.) (1997): Dealing wirh Public Risk in Private Infrastructure, Washington, D.C., Banco Mundial.

Katz, J. M. (1984): Domestic technological innovations and dynamic comparative advantage: further reflections on a comparative case-study program, Journal of Development Ecomsmics, vol 16. $N^{\circ} 1-2$, Amsterdam, Paises Bajos, Elsevier Science Publishers, B.V.
(1998): Crecimiento, cambios estructurales y evolución de la productividad taboral en la industria manufacturera latinoamericana en el período 1970-1996, Santiago de Chile, CEPAL, Unidad de Desarrollo Productivo y Empresarial, mimes.

Katz, J.M. y B. Kosakoff (1998): Aprendizaje tecnológico, desartollo institucional y la microeconomía de la sustilución de importaciones, E, Cardenas, J.A. Ocampo y R. Thorp (eds.), hdustrialization and the State in Latin Americal The Black Lesend and the Post War Yeurx, en prensa.

Krugman, P. (1990): Rethinking International Trade, Cambridge, Massachusetts, MIT Press.

(1995): Development. Geography, and Economic Theor). Cambridge, Massachusetts, MIT Press.

Larraín, G., H. Reisen y J, von Maltzan (1997): Emerging Market Risk and Sovereign Credit Ratings, Technical papers, $N^{\circ} 124$, Paris, OCDE, abril.

Morley, S. A. (1994): Poverty and Inequality in Latin Americt: Past Evidence, Future Prospects, Policy essay, $N^{\circ}$ 13, Washington

D.C., Consejo de Desarrollo de Ultramar.

(1995): Poverty and Inequalit) in Latin Americu: The Impact of Adjustntent and Recovery in the 1980s. Baltimore, Pennsylvania, Johns Hopkins Universily Press.

(1997): Poverty during recovery and reform in Latin America: 1985-1995. Washington, D.C., BID, mayo, mimeo.

Ocampo, J. A. (1996): Provisión privada de servicios saciales: el caso colombiano, Coyantura social, No 14, Santafé de Bogotá, Tercer Mundo Editores, mayo.

(1998a): Distribución del ingreso, pobreza y gasto social en América Latina, Revista de la CEPAL, N 65, LC/G.2033-P, Santiago de Chile, CEPAL.

(1998b): Agricultura y desatrollo rural en América Latina: tendencias, estrategias, hipótesis, Santiago de Chile, CEPAL, agosto, mimen.

orT (Organización Internacioną del Trabajo) (1997): Panorama laboral '97, Ginebra.

Peres, W. (coord.) (1997): Pollíicas de competitividad industrial: América Latina j' el Caribe en los años noventa, México, D.F., Siglo XXI.

Ramos, J. (1998): Una estrategia de desartollo a partir de complejos productivos en torno a los recursos naturales, Revista de la CEPAL, $\mathrm{N}^{\circ} 66$, Santiago de Chile, CEPAL, diciembre.

Robbins, D. (1996): Evidence on Trade and Wages in the Developing World, Technical paper, $N^{*} 119$, París, ocDE, Centro de Desarrollo.

Rodrik, D. (1997): Has Glabalization Gone Too Far?. Washing* ton, D.C., Institute for International Economics (IIE).

Schmidt-Hebbẹl, K., L. Servén y A. Solimano (1996): Savings, investinent, and growth in developing countries: An overview, A. Solimano (ed.), Road Maps to Prosperity: Essays on Growth and Development, Ann Arbor, Michigan, Universily of Michigan Press.

Stiglitz, J. A. (1998): More instruments and broader goals: Moving toward the post-Washington consensus, 1998 Wider Annual Lecture, Helsinki, Universidad de las Naciones Unidas, World Institute for Development Economics Research.

UNCTinD (1997); Informe sobre el comencio y el desarrollo 1997, Ginebra.

Uthoff, A y D. Títelman (1997): La relación entre el ahono externo y el ahorro nacional en contextos de liberalización financiera, R. Ffrench-Davis y H. Reisen (comps.), Flujos de capiral e inversión productiva: lecciones para América Latina, Santiago de Chile, CEPAL/OCDE. 